\title{
Analysis and Design of Fully Integrated Planar Magnetics for Primary-Parallel Isolated Boost Converter
}

Ouyang, Ziwei; Sen, Gökhan; Thomsen, Ole Cornelius; Andersen, Michael A. E.

Published in:

I E E E Transactions on Industrial Electronics

Link to article, DOI:

10.1109/TIE.2012.2186777

Publication date:

2013

Link back to DTU Orbit

Citation (APA):

Ouyang, Z., Sen, G., Thomsen, O. C., \& Andersen, M. A. E. (2013). Analysis and Design of Fully Integrated Planar Magnetics for Primary-Parallel Isolated Boost Converter. I E E E Transactions on Industrial Electronics, 60(2), 494-508. https://doi.org/10.1109/TIE.2012.2186777

\section{General rights}

Copyright and moral rights for the publications made accessible in the public portal are retained by the authors and/or other copyright owners and it is a condition of accessing publications that users recognise and abide by the legal requirements associated with these rights.

- Users may download and print one copy of any publication from the public portal for the purpose of private study or research.

- You may not further distribute the material or use it for any profit-making activity or commercial gain

- You may freely distribute the URL identifying the publication in the public portal 


\title{
Analysis and Design of Fully Integrated Planar Magnetics for Primary-Parallel Isolated Boost Converter
}

\author{
Ziwei Ouyang, Member, IEEE, Gökhan Sen, Student Member, IEEE, Ole C. Thomsen Member, IEEE \\ and Michael A. E. Andersen Member, IEEE
}

\begin{abstract}
A high efficient planar integrated magnetics (PIM) design approach for primary-parallel isolated boost converters is presented. All magnetic components in the converter including two input inductors and two transformers with primary-parallel and secondary-series windings are integrated into an E-I-E core geometry, reducing the total ferrite volume and core loss. The transformer windings are symmetrically distributed into the outer legs of E-cores and the inductor windings are wound on the center legs of E-cores with air gaps. Therefore, the inductor and the transformer can be operated independently. Due to the low reluctance path provided by the shared I-core, the two input inductors can be integrated independently, and also the two transformers can be partially coupled each other. Detailed characteristics of the integrated structure have been studied in this paper. AC losses in the windings and the leakage inductance of the transformer are kept low by interleaving the primary and secondary turns of the transformers substantially. Because of the combination of inductors and transformers, maximum output power capability of the fully integrated module needs to be investigated. Winding loss, core loss and switching loss of MOSFETs are analyzed in-depth in this work as well. To verify the validity of the design approach, a $2-\mathrm{kW}$ prototype converter with two primary power stages is implemented for a fuel cell fed traction applications with 20-50 $\mathrm{V}$ input and 400-V output. An efficiency of $95.9 \%$ can be achieved during $1.5-\mathrm{kW}$ nominal operating conditions. Experimental comparisons between the PIM module and three separated cases have illustrated the PIM module has advantages of lower footprint and higher efficiencies.
\end{abstract}

Index Terms - Core loss, dc-dc converter, fuel cell, inductor, isolated boost, planar integrated magnetics (PIM), transformer and winding loss.

\section{INTRODUCTION}

$\mathrm{D}$ ISTRIBUTED generation systems, back-up systems or traction systems based on fuel cells or batteries, requires high-power high-gain dc-dc converters to boost the low source voltage $(20-50 \mathrm{~V})$ to a higher dc-link voltage $(350-400 \mathrm{~V})$. For safety or EMC reasons, transformer isolation is often required or preferred. As power levels increase, input currents quickly reach levels where paralleling of primary switches become necessary. Since transistors are often operated close to their maximum drain current rating, direct paralleling of MOSFETs may require screening and parameter matching of on-resistance, gain and/or threshold voltages. Slowing switching speed by increasing gate impedance or addition of source inductance may also be required. A new, simple and low cost method to extend power level in isolated boost converters by paralleling of critical high-

Manuscript received August 28, 2011 and accepted for publication January 19, 2012. This work is supported by Flux A/S.

Copyright (C) 2009 IEEE. Personal use of this material is permitted. However, permission to use this material for any other purposes must be obtained from the IEEE by sending a request to pubs-permissions@iee.org

The authors are with the Department of Electrical Engineering, Technical University of Denmark, 2800 Kongens Lyngby, Denmark (e-mail: zo@elektro.dtu.dk; gs@elektro.dtu.dk; oct@elektro.dtu.dk; ma@elektro.dtu.dk). ac-current circuit parts is presented in [1]. It is found that the accurrent loop from the primary switches to the transformer primary windings is a particularly critical area with respect to scaling of power level. This requires extremely low leakage inductance of transformers and stray inductance of the circuit layout in order to achieve high efficiency. With traditional magnetics components, this extreme requirements result a high cost in magnetics components and an impossibility of mass production, although $98.2 \%$ peak efficiency can be achieved in this converter. Moreover, the size of magnetics components also limits its application in practice.

In order to satisfy the requirements of modern power electronics application, magnetics integration with planar core has proven to be an effective means of reducing the converter size and cost, while increasing the converter efficiency. Planar magnetics have unique advantages in terms of increased power density, better cooling capability, modularity and manufacturing simplicity as well as easy implementation of interleaved windings, which make them attractive for high current dc-dc power converter applications [2]-[13]. In recent years, most efforts in integrated magnetics (IM) focus on the current-doubler rectifier due to its suitability for low-output-voltage and highoutput-current applications. Unlike conventional magnetic integration focusing only on core integration, both core and winding integration can be realized in the current-doubler rectifier design, causing lower conduction loss and core loss. As a result, lower overall cost, size as well as higher efficiency can be obtained by the IM design for the current-doubler circuit [2][6] and the dual-inductor isolated boost converter as well [14]. A $1-\mathrm{kW}$ module with $300 \sim 400-\mathrm{V}$ input voltage and $48-\mathrm{V}$ output voltage asymmetrical half-bridge PWM converter employing an integrated $\mathrm{L}-\mathrm{L}-\mathrm{C}-\mathrm{T}$ module is constructed in [7]. Detailed suggestions are given on how a generic, integrated LCT component could be used to implement various resonant converter topologies by merely reconfiguring the external terminals of the integrated components [8]-[9]. An integrated transformer consisted of four step-down transformers wound on a single magnetic core for an interleaved four-phase forward converter has been proposed in [15]. Coupled inductors greatly reduce the steady-state inductor current ripples without sacrificing the transient response as shown in [16]-[19]. A full procedure to generate 2D Finite Element Analysis (FEA) based model for integrated magnetics is presented in [20].

The converter in [1] is a typical application of distributed magnetics. Distributed magnetics functionally split a large magnetic element into small magnetic element which is an efficient way to reduce ac resistance and leakage inductance compared to a large single magnetic component [21]. Over $40 \%$ of the effective winding resistance and $20 \%$ leakage inductance reduction can be achieved by matrix transformers [22], making it very attractive for high current applications. However, increased numbers of components in the distributed magnetics increases the size of the power converters and reduces the power efficiency in the light load due to higher core loss. Therefore, integration of 


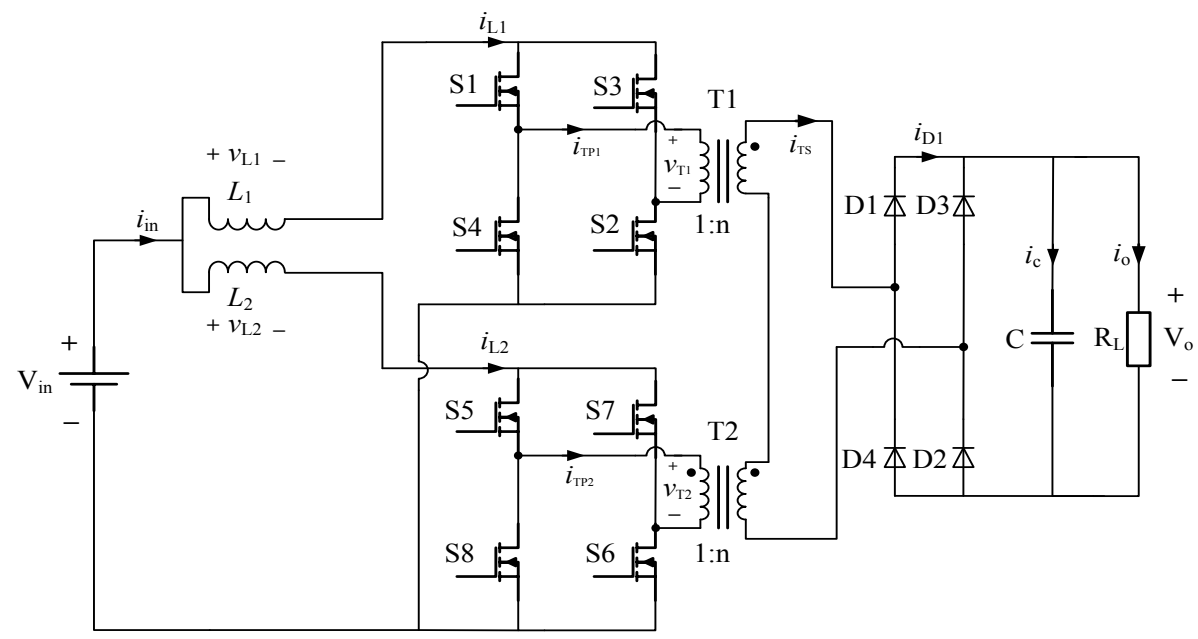

Fig. 1. Primary-parallel isolated boost converter.

distributed magnetics becomes promising. In this paper, a new approach to integrate the distributed magnetics components for the primary-parallel isolated boost converter is presented. All magnetic components in the converter including the two input inductors and two transformers with primary-parallel and secondary-series connected windings are integrated into an E-I-E core geometry, reducing the total ferrite volume and core loss. The transformer windings are symmetrically distributed into the outer legs of E-cores and the inductor windings are wound on the center legs of E-cores with air gaps. Detail characteristics of the integrated structure are presented in Section III. Due to the integration of inductors and transformers, maximum output power capability of the integrated module has to be considered to avoid flux saturation in the core. Core loss estimation for the PIM structure has been investigated in-depth and an effect of core loss under dc bias operation has been considered as well. $\mathrm{AC}$ losses in the windings and leakage inductance of the transformers are kept low by interleaving the primary and secondary turns of the transformers. A detailed power loss analysis is given in section $\mathrm{V}$. To verify the validity of the design approach, a $2-\mathrm{kW}$ prototype converter with two primary power stages is implemented for fuel cell fed traction applications with $20 \sim 50-\mathrm{V}$ input and $400-\mathrm{V}$ output. An efficiency of $95.9 \%$ can be achieved during $1.5-\mathrm{kW}$ nominal operating conditions. Experimental comparisons are presented in section VI show the advantages of low profile and high efficiency for the PIM module. In addition, the proposed PIM approach can solve the start-up problem of the boost converter without adding external Flyback winding [23].

\section{Primary-Parallel Isolated Boost CONVERTER}

Boost derived topologies are preferred in fuel cell applications due to their low input current ripple [24]. Fig.1 shows a primaryparallel isolated boost derived topology suitable for handling high input currents for fuel cell applications. Series connection of transformer secondary windings ensures current sharing during energy transfer cycle when power is transferred to output. In this topology, primary power stages share the same control signals with same phase switching sequence for the corresponding switches which allows a simpler control. Output rectification unit as well as input and output filters are common to both of the primary stages. The paralleling method splits the critical primary high-ac-current-loop into two smaller loops. Each of the smaller

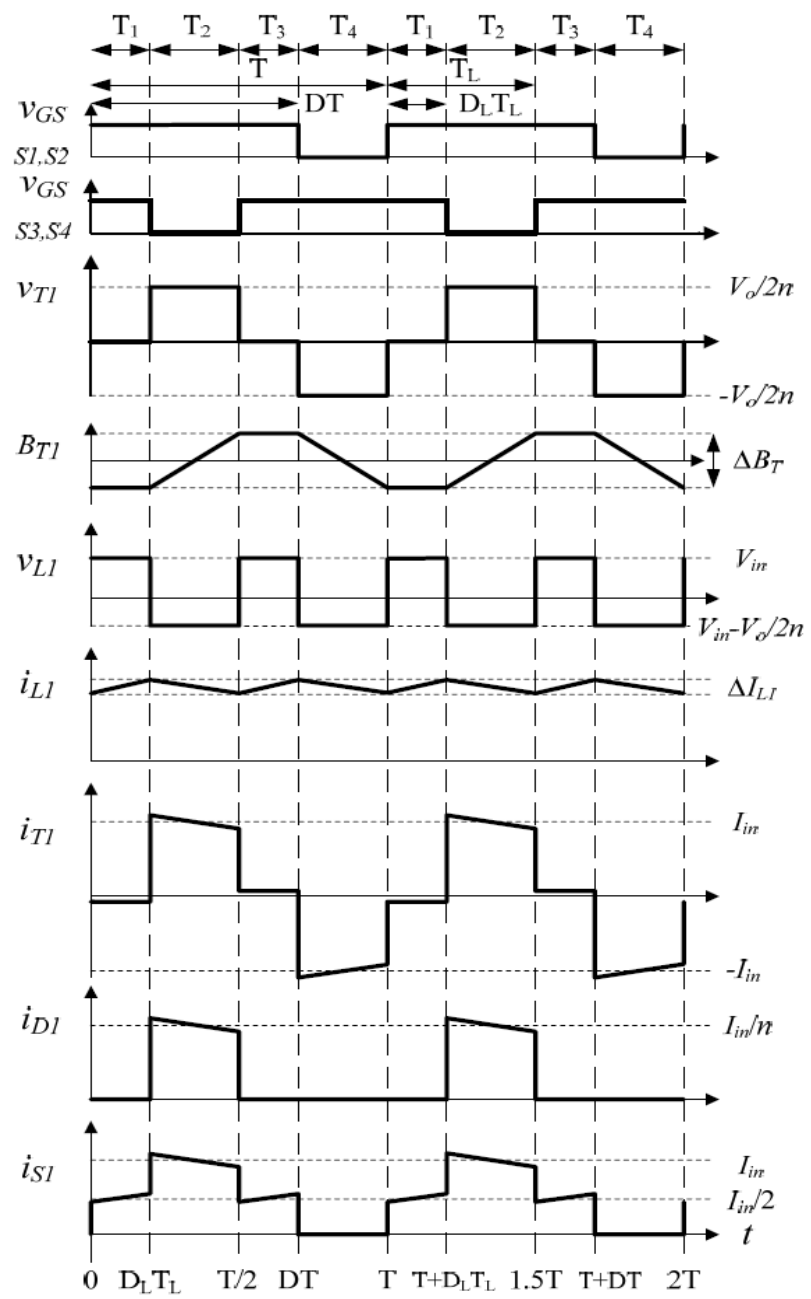

Fig. 2. Timing diagram and basic waveforms for primary-parallel isolated boost converter.

loops only needs to switch half of the input current thereby achieving much faster current switching and thus higher conversion efficiency. Since the two transformers $T_{1}$ and $T_{2}$ share input current and power level, a higher turns ratio transformer in the conventional full-bridge isolated boost converter can be replaced by two individual transformers with lower turns ratio which allows a simpler design and manufacturing of the transformers. 


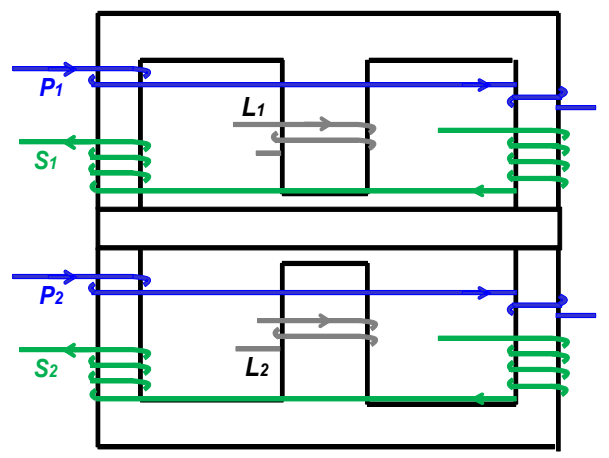

(a)

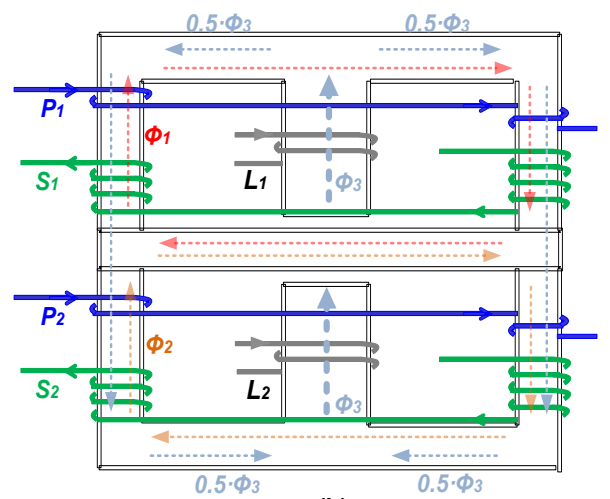

(b)

Fig. 3. Proposed E-I-E integrated magnetic structure (a) and its instantaneous flux distribution (b).

Since the two primary stages operate synchronously utilizing the same control signals, a single stage is analyzed as follows. Fig.2 shows basic waveforms of the primary-parallel isolated boost converter. Primary switches, $S_{1} \sim S_{4}$, are hard switched and operated in pairs, $S_{1} \sim S_{2}$ and $S_{3} \sim S_{4}$ respectively. Driving signals are $180^{\circ}$ phase shifted. Switch transistor duty cycle, $D$, is above $50 \%$ to ensure switch overlap and thus a continuous current path for the boost inductor current. The basic converter operation can be divided into four stages [24].

1) Stage $1\left(T_{1}\right)$ : All switches, $S_{1} \sim S_{4}$, are on and the inductor is charged. All rectifier diodes, $D_{I} \sim D_{4}$, are off and current in the transformer secondary winding is zero;

2) Stage $2\left(T_{2}\right)$ : The first energy transfer period, $T_{2}$, starts when switches, $S_{3}$ and $S_{4}$, are turned off. Inductor energy discharges with its current flowing through primary switch, $S_{I} \sim S_{2}$, and transformer, $T_{1}$ primary. The current in the secondary side flows through the rectifier diodes, $D_{1} \sim D_{2}$, and the output capacitor, $C$.

3) Stage $3\left(T_{3}\right)$ : Works the same as stage 1 , all switches are turned on, the inductor is charged and the inductor current, $i_{L l}$, increases linearly;

4) Stage $4\left(T_{4}\right)$ : The second energy transfer cycle, $T_{4}$, starts when switches, $S_{1}$ and $S_{2}$, are turned off. Inductor energy discharges with its current flowing through primary switches, $S_{3} \sim S_{4}$, transformer, $T_{1}$ primary. The current in the secondary side flows through the rectifier diodes, $D_{3}$ and $D_{4}$, and the output capacitor, $C$.

\section{MODELING OF INTEGRATED MAGNETICS}

Two separated transformers and one boost inductor are integrated into an E-I-E core geometry for hybrid dc-dc converter in [25]. In this study, an additional inductor is added into a combined E-I-E core geometry where two independent transformers, $T_{1}$ and $T_{2}$, and two boost inductors, $L_{1}$ and $L_{2}$, are integrated. Fig. 3 shows the proposed integrated magnetics structure. The windings of each transformer are symmetrically distributed into the outer legs of the two E-cores. $L_{1}$ and $L_{2}$ are wound on the center legs of E-cores with air gaps. The middle Icore provides a low reluctance return path where a complete flux cancellation can be achieved since the two transformers, $T_{l}$ and $T_{2}$, operate with in-phase currents utilizing the same control signals. In fact, the shared I-core could be removed where E-I-E geometry becomes E-E geometry since zero flux is in the shared I-core. However, the two inductors, $L_{1}$ and $L_{2}$ will be fully direct coupled if the shared I-core is removed. This results in a huge spike of inductor current at commutation point if there is any small mismatch in two primary stages [26]. Accordingly, the effect of the shared I-core is to decouple the two inductors. The flux generated by the transformer windings circulate only through the outer legs of the E-cores, which does not affect the inductor's behavior. As shown in Fig.3 (b), flux $\Phi_{3}$ (include dc component) generated by the two input inductor windings goes through the two E-cores, and no dc flux exists in the shared Icore due to the cancellation. As seen in Fig.3, at a certain time period, half of $\Phi_{3}$ increases the total flux in the right leg together with $\Phi_{1}$ and $\Phi_{2}$ and the other half of $\Phi_{3}$ decreases it in the left side. A reverse situation will occur during the next time period. As a result, $\Phi_{3}$ will not affect transformer's behavior. Hereby, the transformers and the inductors are not coupled electromagnetically although the windings are wound in the same core. The flux waveforms in each leg are presented in Fig.9. The proposed structure features an uncoupled technique for all magnetic components in the primary-parallel converter, and there may not have other possible configuration unless using the customer design core geometries instead of the standard core geometries.

Fig.4 shows an equivalent magnetic reluctance model of the PIM module where $R_{l}$ is the reluctance of the outer leg of E-core, $R_{2}$ is the reluctance of I-core and $R_{C}$ represents the reluctance of the center leg of E-core. $R_{C}$ is much bigger than $R_{1}$ and $R_{2}$ due to the air gaps in the center legs. Since the transformers and the inductors are not coupled electromagnetically, the equivalent magnetic model can be divided into two parts as shown in the bottom of Fig.4. The left figure represents the magnetic model associated with $T_{1}$ and $T_{2}$. The flux $\Phi_{1}$ and $\Phi_{2}$ does not flow in the center legs of the E-core. The flux $\Phi_{1}$ is identical to the flux $\Phi_{2}$ due to two transformers operate with in-phase currents utilizing the same control signals. Therefore, the flux $\Phi_{1}$ and $\Phi_{2}$ in the shared I-core are fully cancelled. The right figure represents the magnetic model of the two inductors, $L_{I}$ and $L_{2}$.

With the assumption that the leakage flux through the air and the fringing effect are negligible, equations (1) (3) can be derived according to the magnetic model,

$$
\begin{aligned}
& N_{1} \cdot i_{m 1}=\Phi_{1} \cdot\left(2 R_{1}+R_{2}\right)+\left(\Phi_{1}-\Phi_{2}\right) \cdot R_{2} \\
& N_{2} \cdot i_{m 2}=\Phi_{2} \cdot\left(2 R_{1}+R_{2}\right)+\left(\Phi_{2}-\Phi_{1}\right) \cdot R_{2} \\
& 2 \cdot N_{L} \cdot i_{L}=2 \cdot \Phi_{3} \cdot R_{c}+0.5 \cdot \Phi_{3} \cdot\left(2 R_{1}+R_{2}\right)
\end{aligned}
$$

where $N_{1}$ and $N_{2}$ are the number of primary turns for the transformers $T_{I}$ and $T_{2}$ respectively. $N_{L}$ is the number of turns for 

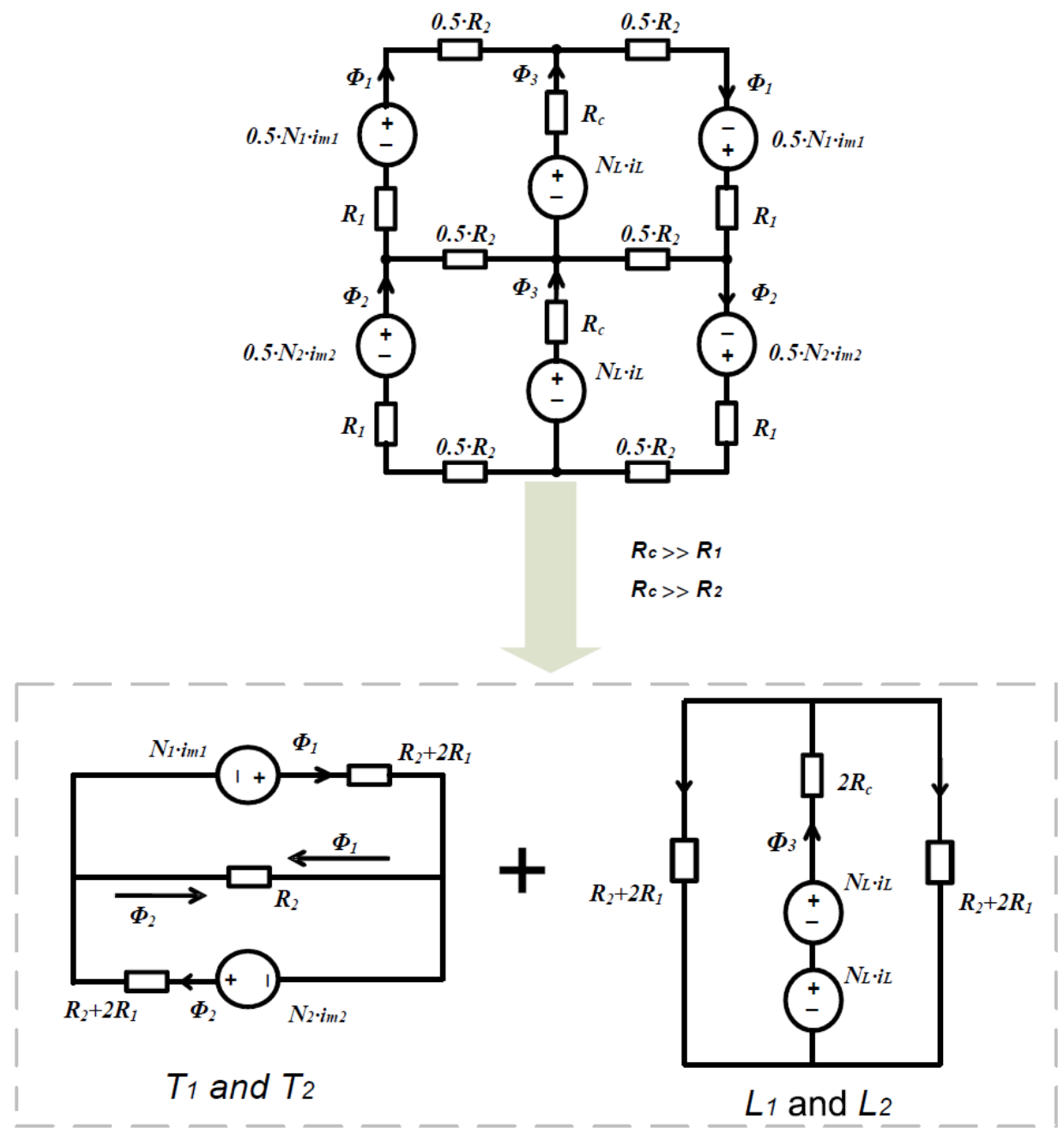

Fig. 4. Magnetic reluctance model of the PIM structure.

the inductors $L_{1}$ or $L_{2}$. The rate of change on $\Phi_{1}$ and $\Phi_{2}$ are the same over the entire period. Based on the Faraday's law, magnetizing inductances can be obtained,

$$
\begin{gathered}
L_{m 1}=\frac{N_{1}^{2}}{2 R_{1}+R_{2}} \\
L_{m 2}=\frac{N_{2}^{2}}{2 R_{1}+R_{2}} \\
L_{1}=L_{2}=\frac{2 \cdot N_{L}^{2}}{2 \cdot R_{c}+R_{1}+0.5 \cdot R_{2}}
\end{gathered}
$$

For a single separated transformer with the same winding arrangement at the outer leg, the magnetizing inductance is equal to, $L_{m}=N^{2} / 2\left(R_{1}+R_{2}\right)$, where $N$ is the number of primary turns for the single transformer. It is important to note that the integrated transformers have higher magnetizing inductances than the single case when both $T_{1}$ and $T_{2}$ have same current excitation. This is due to the fact that the mutual inductance between the two transformers $T_{1}$ and $T_{2}$ increases the magnetizing inductance. The coupling effect between $T_{1}$ and $T_{2}$ is shown in appendix.

\section{Magnetics Design Consideration}

The advantages of this structure are highlighted in [27]. TableI has shown the integrated module has advantages in the cost, the efficiency, the size and the manufacturability at expense of the design process. Another drawback of the PIM module is to limit the maximum output power capability due to the overlapped flux. According to Faraday's law and Ampere's law, the peak flux densities of each magnetic component in the PIM module can be derived,

$$
\begin{gathered}
\hat{B}_{T}=\frac{V_{\text {out }} \cdot(1-D)}{4 \cdot n \cdot f \cdot N \cdot A_{e}} \\
\hat{B}_{L}=\frac{\mu_{0} \cdot N_{L} \cdot I_{p k}}{l_{g}} \\
\hat{B}_{L a c}=\frac{\mu_{0} \cdot N_{L} \cdot \Delta I}{2 \cdot l_{g}}
\end{gathered}
$$

where the peak current for the inductor is,

$$
I_{p k}=I_{d c}+\frac{\Delta i}{2}=\frac{P_{0}}{\eta \cdot V_{i n}}+\frac{V_{i n} \cdot(D-0.5) \cdot l_{g}}{2 \cdot f \cdot \mu_{0} \cdot N_{L}^{2} \cdot A_{e}}
$$


This article has been accepted for publication in a future issue of this journal, but has not been fully edited. Content may change prior to final publication.

TABLE I

COMPARISONS BETWEEN INTEGRATED AND CONVENTIONAL MAGNETIC COMPONENTS

\begin{tabular}{|c|c|c|}
\hline & Integration & Convention \\
\hline Cost & Low & High \\
\hline Efficiency & High & Low \\
\hline Size & Small & Large \\
\hline Manufacturability & Simple & Complex \\
\hline Design process & Complex & Simple \\
\hline
\end{tabular}

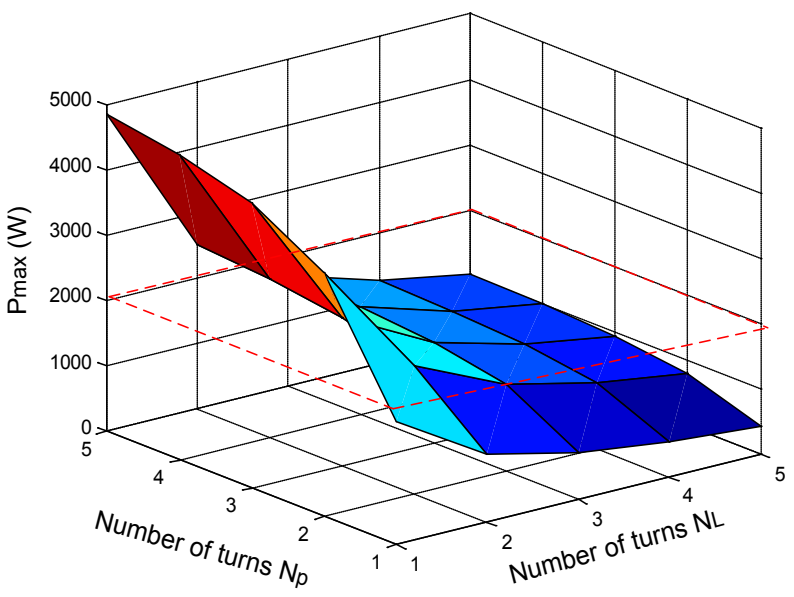

Fig. 5. 3D plot of maximum output power capability.

$\widehat{B}_{T}$ and $\widehat{B}_{L}$ represent the peak flux density of each transformer $\left(T_{1}\right.$ or $\left.T_{2}\right)$ and inductor $\left(L_{1}\right.$ or $\left.L_{2}\right)$ respectively. $\widehat{B}_{\text {Lac }}$ is the peak flux density of ac component of each inductor as shown in Fig.9. The same number of primary turns for the two transformers, $N_{I}=N_{2}=N$, is assumed. $D$ is the switching duty cycle, $n$ is the turns ratio of transformers, $f$ is the switching frequency, $A_{e}$ is the cross-section of the outer leg of E-core, $l_{g}$ is the length of air gap in each center leg, $P_{o}$ is the output power, $\eta$ is the efficiency of the converter, $\mu_{0}$ is the permeability of air and $V_{\text {in }}$ represents the input voltage. In order to avoid flux saturation in the PIM module, the following equations are required,

$$
\begin{gathered}
\hat{B}_{T}+\hat{B}_{L}=\frac{V_{\text {out }} \cdot(1-D)}{4 \cdot n \cdot f \cdot N \cdot A_{e}}+\frac{\mu_{0} \cdot N_{L} \cdot P_{0}}{\eta \cdot V_{\text {in }} \cdot l_{g}}+\frac{V_{\text {in }} \cdot(D-0.5)}{2 \cdot f \cdot N_{L} \cdot A_{e}} \\
\leq B_{\text {sat }}
\end{gathered}
$$

The 3D graph in Fig.5 shows the relationship among the output power $P_{o}$, the number of turns of primary winding $N_{P}$, and the number of turns of inductor winding $N_{L}$ which has been plotted based on (11) with $100 \mathrm{kHz}$ switching frequency and $0.5 \mathrm{~mm}$ airgap. In order to design a 2-kW PIM module, the number of inductor turns, $N_{L}$, cannot exceed 3 turns. Its $2 \mathrm{D}$ relationship of $N_{P}$ and $N_{L}$ corresponding to the maximum output power capabilities is illustrated in Fig.6. The maximum output power can be enhanced by increasing the number of primary turns $N$ or decreasing the number of inductor turns $N_{L}$. Fig.7 illustrates the

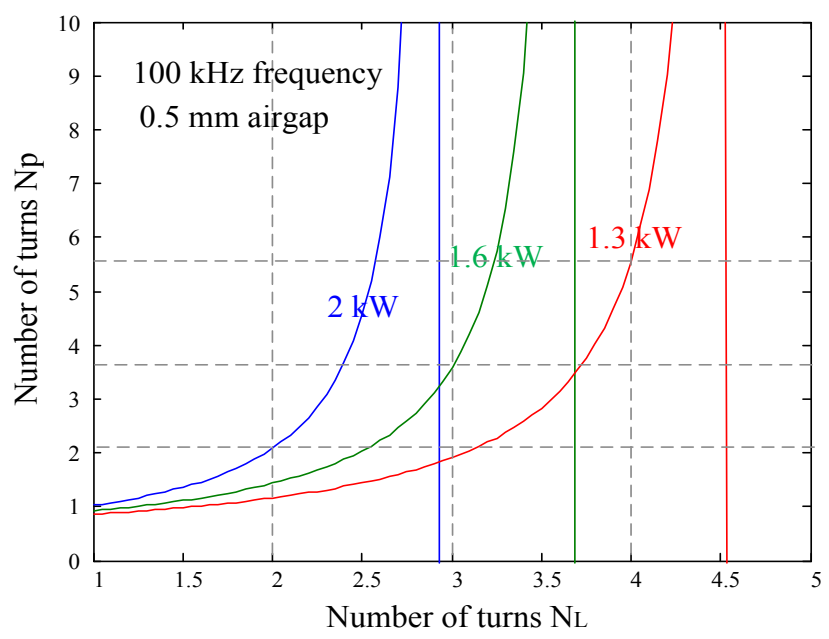

Fig. 6. Relationship of $\mathrm{N}_{\mathrm{L}}$ and $\mathrm{N}_{\mathrm{P}}$ under different output powers.

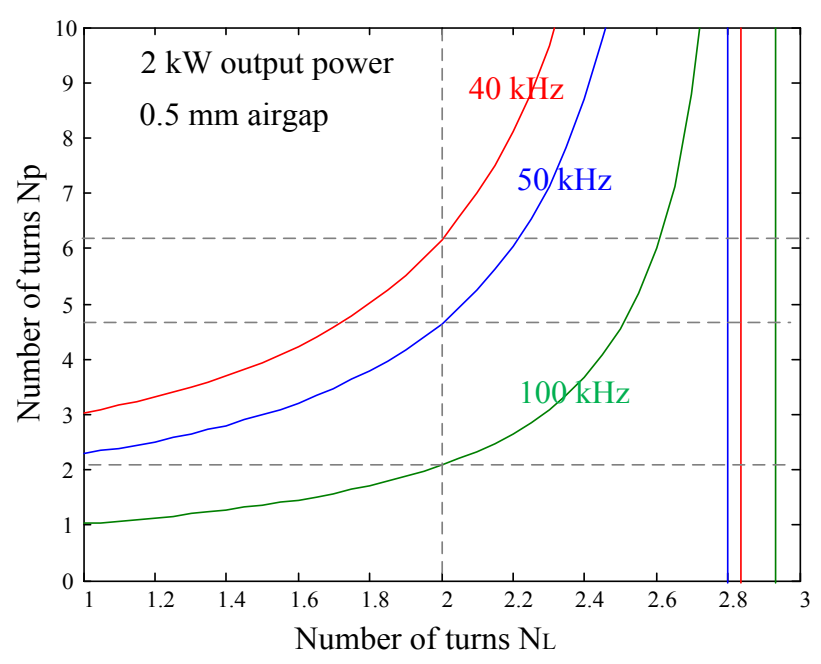

Fig. 7. Relationship of $N_{L}$ and $N_{P}$ under different switching frequencies.

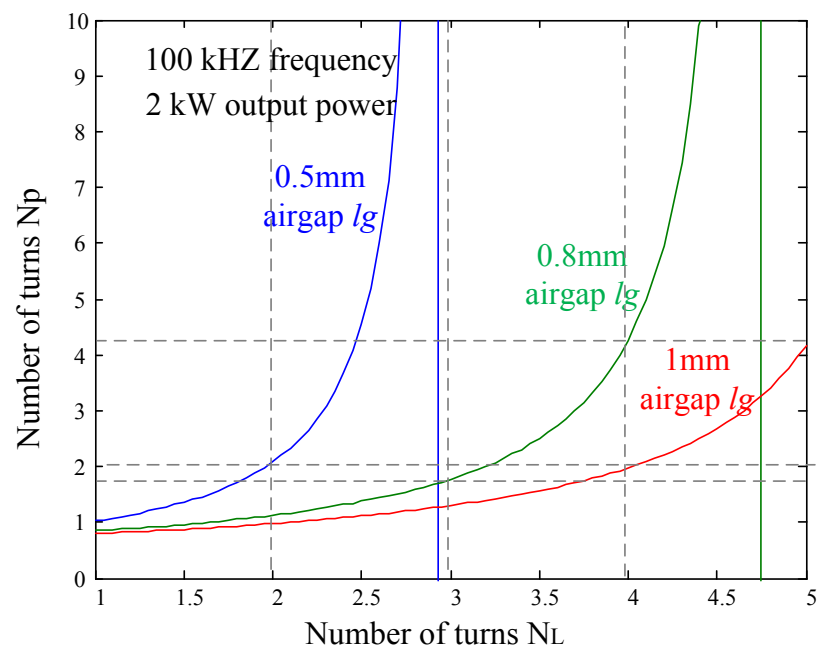

Fig. 8. Relationship of $\mathrm{N}_{\mathrm{L}}$ and $\mathrm{N}_{\mathrm{P}}$ under different airgaps

fact that maximum output power capability of the PIM module is decreased by reducing the switching frequency. Of course, more energy can be stored by using large airgap, resulting in a large output power capability for the PIM module as illustrated in Fig.8. However, a large airgap results in a low inductance which causes a high current ripple in the circuit for the same number of turns and thereby reduces the efficiency. Moreover, a larger 


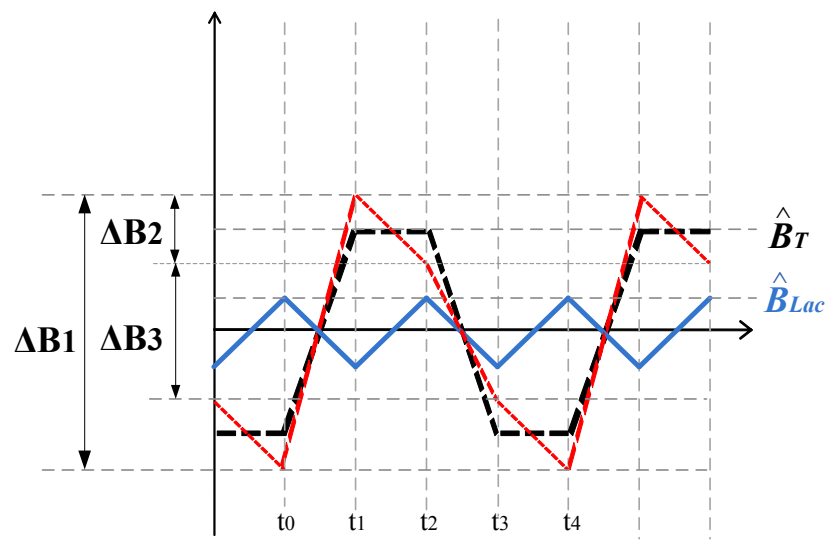

(a) left side leg

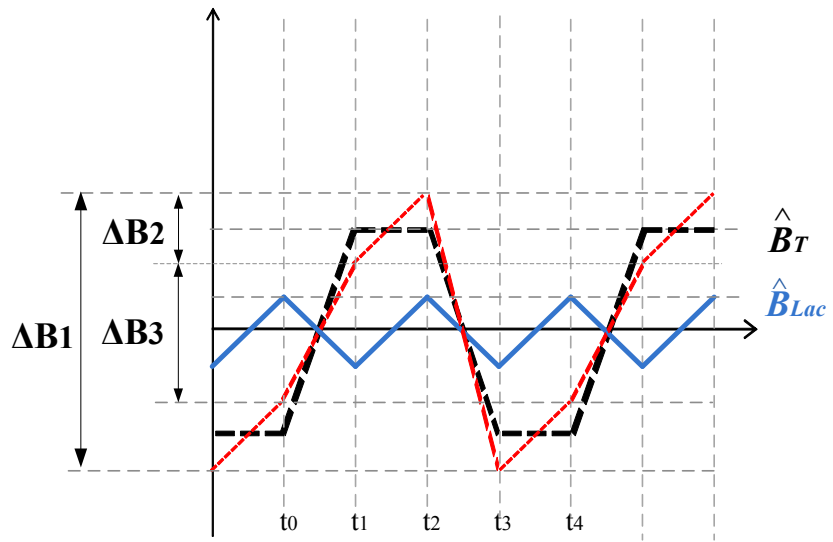

(b) right side leg

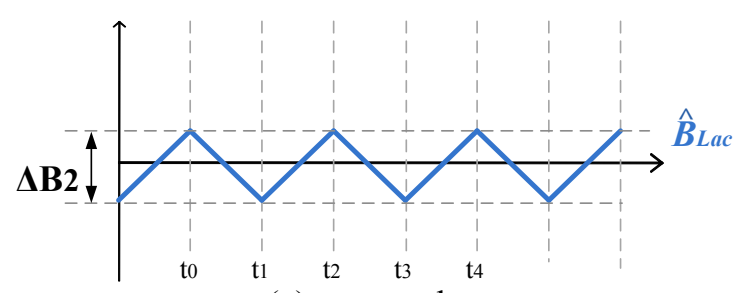

(c) center leg

Fig. 9. Flux density waveforms in each leg of the PIM module.

winding loss will be induced due to the fringing effect. Although the maximum output power can also be increased by using higher number of turns of primary winding $N$, larger winding losses and leakage inductances of the transformers $T_{1}$ and $T_{2}$ will be produced, reducing the efficiency as well. Unavoidable tradeoff in the power loss exists in the PIM design and the detailed power losses analysis will be given in section $\mathrm{V}$.

\section{POWER LOSS ANALYSIS}

\section{A. Core Loss}

Core loss separation approach [28] assumes that three fundamental effects are contributing to core losses: static hysteresis loss, eddy current loss and excess eddy current loss. The approach of loss separation has a practical disadvantage: such models are based on parameters, which are not always available and difficult to extract. The most commonly used equation that characterizes core losses is the Steinmetz equation (SE), a curve-fitting expression of measured data under sinusoidal excitation.

$$
P_{v}=k \cdot f^{\alpha} \cdot\left(\frac{\Delta B}{2}\right)^{\beta}
$$

where $k, \alpha, \beta$ are material parameters , $\Delta B$ is peak-to-peak flux density of a sinusoidal excitation with switching frequency $f, P_{v}$ is time-average core loss per unit volume. Unfortunately, the Steinmetz equation is only valid for sinusoidal excitation. This is a significant drawback since in power electronics applications the core material is normally exposed to non-sinusoidal flux waveforms. Core loss due to non-sinusoidal waveforms can far exceed the loss due to sinusoidal waveforms, even if the frequencies and the peak-to-peak flux densities are identical [29]. In order to determine losses for a wider variety of waveforms, some modified expressions including modified Steinmetz expression (MSE) [30], generalized Steinmetz equation (GSE)
[31], improved GSE (IGSE) [32], improved IGSE (I ${ }^{2}$ GSE) [33], natural Steinmetz extension (NSE) [34], equivalent elliptical loop (EEL) [35] and waveform coefficient Steinmetz equation (WCSE) [36] were introduced. A complete comparison among these modified empirical methods shows that the IGSE have the best loss determination with a wide variety of waveforms [29].

$$
P_{v}=\frac{1}{T} \cdot \int_{0}^{T} k_{i} \cdot\left|\frac{d B(t)}{d t}\right|^{\alpha} \cdot \Delta B^{\beta-\alpha} \cdot d t
$$

where,

$$
k_{i}=\frac{k}{(2 \pi)^{\alpha-1} \cdot \int_{0}^{2 \pi}|\cos \theta|^{\alpha} \cdot 2^{\beta-\alpha} \cdot d \theta}
$$

(13) shows the IGSE expression where $k, \alpha$ and $\beta$ are the same parameters used in the Steinmetz equation (12). The angle $\theta$ represents the phase angle of the sinusoidal waveform. Applying a piecewise linear model (PWL) to any waveform and then combining with the IGSE, leads to an easy-to-use expression for accurate calculation of losses with any flux waveform, without requiring extra characterization of material parameters beyond the parameters of the Steinmetz equation.

It is necessary to know the flux density waveforms to estimate core loss properly using IGSE. Fig.9 shows the flux density waveforms in each leg of the PIM module.

1) In the time period $t_{0} \sim t_{l}$, the transformer flux $\Phi_{T}$ and the inductor flux $\Phi_{L}$ are adding together in the left side legs of both E-cores. On the other hand, they are cancelling in the right side legs.

2) During the time period $t_{l} \sim t_{2}$, the rate of change of $\Phi_{T}$ is zero, and therefore ac flux $\Delta B_{2}$ in the two side legs are identical to ac flux on the inductor $\Delta B_{L}$.

3) $t_{2} \sim t_{3}$, is the opposite of the period $t_{0} \sim t_{1}$ where the transformer flux $\Phi_{T}$ and the inductor flux $\Phi_{L}$ are opposing in the left side legs of both E-cores. Meanwhile, they are added in the 
TABLE II

Calculated Results For Core Loss Without Pre-Magnetization

\begin{tabular}{|c|c|c|c|c|}
\hline \multirow{2}{*}{$\begin{array}{c}\text { Input } \\
\text { voltage }\end{array}$} & \multicolumn{4}{|c|}{ Core loss } \\
\cline { 2 - 5 } & $\begin{array}{c}\text { Left side leg } \\
P_{C L}\end{array}$ & $\begin{array}{c}\text { Right side leg } \\
P_{C R}\end{array}$ & $\begin{array}{c}\text { Center leg } \\
P_{C C}\end{array}$ & Total \\
\hline $\mathrm{V}_{\text {in }}=30 \mathrm{~V}$ & $5.95 \mathrm{~W}$ & $5.95 \mathrm{~W}$ & $0.09 \mathrm{~W}$ & $12 \mathrm{~W}$ \\
\hline $\mathrm{V}_{\text {in }}=45 \mathrm{~V}$ & $13.43 \mathrm{~W}$ & $13.43 \mathrm{~W}$ & $0.01 \mathrm{~W}$ & $26.87 \mathrm{~W}$ \\
\hline
\end{tabular}

TABLE III

ERROR ANALYSIS BETWEEN NORMAL STEINMETZ EQUATION AND IMPROVED STEINMETZ EQUATION

\begin{tabular}{|c|c|c|c|c|}
\hline & & $\begin{array}{c}\text { SE with eqn. } \\
\text { (12) }\end{array}$ & $\begin{array}{l}\text { IGSE with } \\
\text { eqn. (13) }\end{array}$ & Error \\
\hline \multirow{3}{*}{$V_{\text {in }}=30 \mathrm{~V}$} & $\begin{array}{c}\text { Left side leg } \\
\qquad P_{C L}\end{array}$ & $3.47 \mathrm{~W}$ & $5.95 \mathrm{~W}$ & $42 \%$ \\
\hline & $\begin{array}{c}\text { Right side } \\
\text { leg } P_{C R}\end{array}$ & $3.47 \mathrm{~W}$ & $5.95 \mathrm{~W}$ & $42 \%$ \\
\hline & $\begin{array}{c}\text { Center leg } \\
P_{C C} \\
\end{array}$ & $0.01 \mathrm{~W}$ & $0.09 \mathrm{~W}$ & $90 \%$ \\
\hline \multirow{3}{*}{$\mathrm{V}_{\mathrm{in}}=45 \mathrm{~V}$} & $\begin{array}{c}\text { Left side leg } \\
P_{C L} \\
\end{array}$ & $7.9 \mathrm{~W}$ & $13.43 \mathrm{~W}$ & $42 \%$ \\
\hline & $\begin{array}{c}\text { Right side } \\
\text { leg } P_{C R}\end{array}$ & $7.9 \mathrm{~W}$ & $13.43 \mathrm{~W}$ & $42 \%$ \\
\hline & $\begin{array}{c}\text { Center leg } \\
P_{C C}\end{array}$ & $0.001 \mathrm{~W}$ & $0.01 \mathrm{~W}$ & $90 \%$ \\
\hline
\end{tabular}

right side legs.

4) $t_{3} \sim t_{4}$, is the same as $t_{1} \sim t_{2}$. The red dashed lines shown in Fig.9 (a) and Fig.9 (b) represent the overall flux density waveforms in the two side legs respectively. Since the flux of transformer $\Phi_{T}$ does not go through the center leg, the overall flux density waveform in the center leg is only dependent on the flux of inductor $\Phi_{L}$.

The core loss can be calculated individually for each leg. For the applied flux waveform as illustrated in Fig.9, by using (13) together with PWL method, the following equations of core loss for each leg is obtained,

$$
\begin{gathered}
P_{v s}=k_{i} \cdot f^{\alpha} \cdot\left[\left(\Delta B_{1}{ }^{\beta}+\Delta B_{3}{ }^{\beta}\right) \cdot(1-D)^{1-\alpha}+2 \cdot \Delta B_{2}{ }^{\beta}\right. \\
\left.\cdot(D-0.5)^{1-\alpha}\right] \\
P_{v c}=4 \cdot k_{i} \cdot f^{\alpha} \cdot \Delta B_{2}{ }^{\beta} \cdot(D-0.5)^{1-\alpha}
\end{gathered}
$$

where,

$$
\begin{gathered}
\Delta B_{1}=2 \cdot\left(\hat{B}_{T}+\hat{B}_{L a c}\right) \\
\Delta B_{2}=2 \cdot \widehat{B}_{L a c} \\
\Delta B_{3}=\Delta B_{1}-\Delta B_{2}=2 \cdot\left(\hat{B}_{T}-\hat{B}_{L a c}\right)
\end{gathered}
$$

and $P_{v S}$ is the core loss per unit volume in each side leg and $P_{v c}$ is the core loss per unit volume in the center leg. The flux $\Phi_{1}$ is identical to the flux $\Phi_{2}$ due to two transformers operating with in-phase currents utilizing the same control signals. The two flux $\Phi_{1}$ and $\Phi_{2}$ are fully cancelled in the shared I-core where zero core loss ideally can be achieved. Table II shows the calculated results of core loss in each leg with different input voltages. The worst case for the core loss is in high input voltage where a

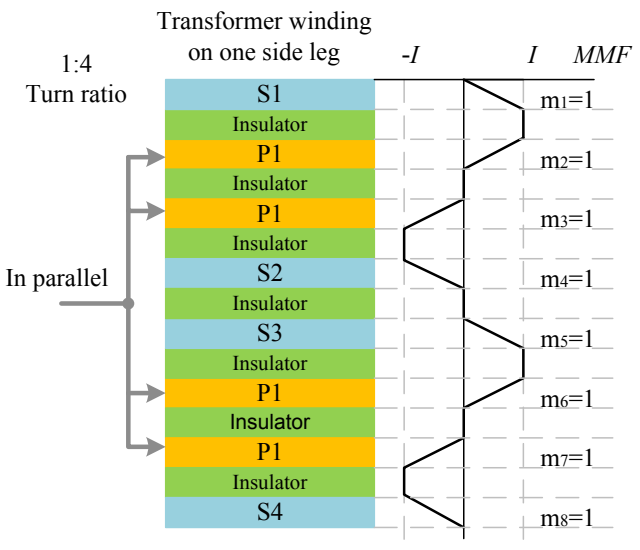

Fig. 10. Winding arrangement and MMF distribution for the transformer windings wound on one of the outer legs.

higher peak flux is induced. In order to illustrate the inaccuracy of SE with (12), Table III shows an error analysis between SE and IGSE for the core loss of the PIM module.

However, the aforementioned calculations are based on the IGSE formula which neglects the fact that core losses vary under dc bias conditions, i.e. the Steinmetz parameters change under dc bias condition. When a core operates under de bias condition, the core loss still can be described using the Steinmetz equation (12) or the IGSE (13). However, the Steinmetz parameters must be adjusted according to the dc bias present. Pre-magnetization $H_{D C}$ causes changes in the Steinmetz parameters $\beta$ and $k_{i}$, but not in the parameter $\alpha$. For many materials, the impact of a dc bias cannot be neglected as it may increase the core loss by a factor of more than two [37]. According to Steinmetz Pre-magnetization Graph (SPG) of the material ferrite N87 in [37], the core losses in this converter under different $\mathrm{dc}$ bias can be approximately estimated by multiplying the coefficient of SPG. The results are shown in Table VI and Table VII respectively.

\section{B. Winding Loss}

Winding losses in transformers increase dramatically with high frequency due to eddy current effects. Eddy current losses, including skin effect and proximity effect losses seriously impair the performance of transformers in high-frequency power conversion applications. Both the skin effect and the proximity effect cause the current density to be non-uniformly distributed in the cross-section of the conductor, and thus cause a higher winding resistance at higher frequency. The most commonly used equation that characterizes winding losses is the Dowell's equation [38]-[40],

$$
\frac{R_{a c, m}}{R_{d c, m}}=\frac{\varepsilon}{2} \cdot\left[\frac{\sinh \varepsilon+\sin \varepsilon}{\cosh \varepsilon-\cos \varepsilon}+(2 m-1)^{2} \cdot \frac{\sinh \varepsilon-\sin \varepsilon}{\cosh \varepsilon+\cos \varepsilon}\right]
$$

where $\varepsilon$ is the ratio of copper thickness $h$ to the skin depth $\delta$ in a given frequency, and $m$ is defined as a ratio in (17),

$$
m=\frac{F(h)}{F(h)-F(0)}
$$

where $F(0)$ and $F(h)$ are magneto motive forces (MMFs) at the limits of a layer as shown in Fig.10. The first term in (16) describes the skin effect and the second term represents the proximity effect. The proximity effect loss, in a multilayer 


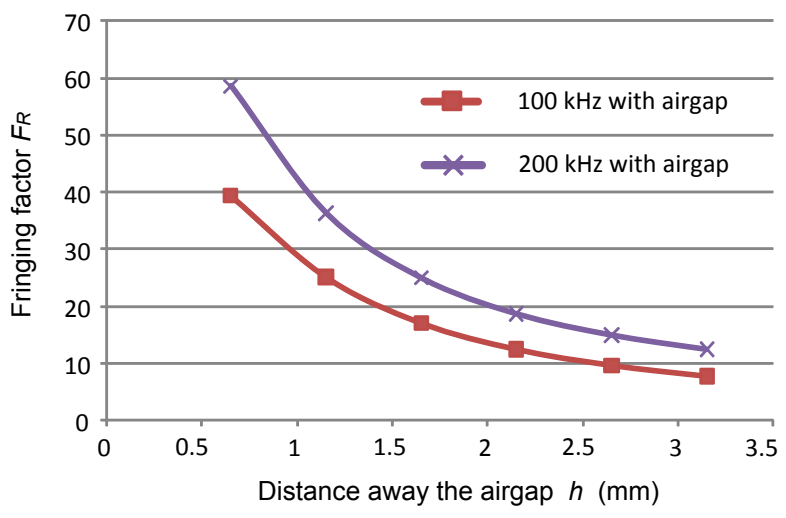

Fig. 11. Fringing factor $F_{R}$ with different winding locations.

winding, may strongly dominate over the skin effect loss depending on the winding arrangement [40]. Interleaving transformer windings may reduce the proximity loss significantly when the primary and secondary currents are in-phase [41]. Similarly, the leakage inductance of a transformer can also be significantly reduced [42]. Fig.10 shows the winding arrangements and MMF distributions along the vertical direction for the windings of transformer $T_{1}$ or $T_{2}$ wound on one of the outer legs. The MMF ratio $m$ for each layer is equal to 1 which results in a lower ac resistance and leakage inductance. As seen in (16), ac resistance is not only related to MMF ratio $m$, but also to the ratio $\varepsilon$. A thinner copper can minimize the eddy current effect but a higher dc resistance will be compromised. Therefore, for a given frequency and winding arrangement, minimum ac resistance can be obtained by selection of proper copper thickness. Considering the cost of $\mathrm{PCB}$ and manufacturing simplicity, a 4-oz PCB copper thickness has been chosen for both primary and secondary windings for the experiment in this paper. In practice, $\mathrm{PCB}$ winding has a larger resistance compared to the calculation due to PCB vias and the fabrication tolerances.

It is noted that the validity of the expression (16) relies on negligible distances between consecutive turns, between adjacent layers, between the conductor edge and the magnetic core. Furthermore, the expression (16) is only valid for sinusoidal excitation waveform. Winding loss calculation for any current waveform to correct Dowell's assumptions can be found in [39]. Also [43] gives generalized correction factors to be applied to Dowell's resistance factor expression. However, these factors are usually derived from elaborated formulas and have to be determined from complicated coefficient tables.

Ferrite core has a limited saturation flux density, which requires inclusion of an airgap in the magnetic path in order to store energy for the inductors $L_{1}$ and $L_{2}$. A large airgap results in fringing flux which has two effects. First, the inductance is increased due to the effective increase in the airgap crosssectional area, which decreases the reluctance of the gap. Second, the fringing flux induces eddy currents in the surface of nearby conductors, which causes a higher ac resistance and thereby increases the conduction loss. The fringing effect can be expressed as follows,

$$
R_{a c}=F_{R} \cdot R_{d c}
$$

where $F_{R}$ represents the factor of fringing effect. Dowell's equation (16) does not include the fringing effect caused by the airgap. Therefore $F_{R}$ in this case is much higher than the one
TABLE IV

SWITCHING LOSS PARAMETERS

\begin{tabular}{|c|c|}
\hline Parameters & Values \\
\hline Clamp voltage, $V_{C}$ & $84 \mathrm{~V}\left(\right.$ at $\left.100^{\circ} \mathrm{C}\right)$ \\
\hline Gate to source voltage at $V_{G S}\left(i_{S}\right)$ & $4.1 \mathrm{~V}$ \\
\hline Common source inductance, $L_{C S}$ & $11.3 \mathrm{nH}$ \\
\hline Stay and leakage inductance, $L_{X}$ & $52.7 \mathrm{nH}$ \\
\hline
\end{tabular}

calculated by Dowell's equation. How the fringing field affects the high frequency winding loss and how to configure the windings to minimize the effect of the fringing field of the air gap have been investigated recently in [44]-[45]. The PCB windings are kept far away from the airgap in order to minimize the fringing effect in this work. The fringing effect in the PIM module has been considered by using FEA simulation tool. Fig.11 shows FEA simulation results of the fringing effect of an airgap at different windings locations. Almost 60 times of $\mathrm{dc}$ resistance can be obtained when the windings are close to the airgap and with $200 \mathrm{kHz}$ inductor current ripple.

\section{Switching Loss of MOSFETS}

Hard switching isolated dc-dc converters suffer increased switching loss due to leakage and stray inductances of the isolation transformer and layout, respectively. Both precise calculation and measurement of the switching losses are not straightforward due to voltage dependant parameters of the MOSFTEs like the output capacitor and time scale mismatch of MOSFET drain current and voltage waveforms. MOSFETs used in boost-type isolated dc-dc converters experience inductive switching since neither the input nor the output capacitors can directly clamp their drain-to-source voltages. This condition results in switching spikes occurring on top of the drain-tosource voltage during the turn-off process [46].

During turn-off, drain-to-source capacitance voltage of the MOSFET rises with a speed determined by the current sinking capability of the gate driver circuit in order to charge the Miller capacitance. Mostly this charging is lossless when performed by an inductive element which is the case in boost type converters. However during the turn-on process the stored energy in the output capacitor of the MOSFET is dissipated. This loss may become significant in higher voltage and frequency levels.

Apart from the capacitive switching loss considerations, additional factors come into play in high input current $\mathrm{dc} / \mathrm{dc}$ applications. Common source inductance (Fig.12) and gate driver voltage become the limiting factors for the MOSFET current turn off speed [47]. The negative rate of change of the drain current during turn-off induces a positive gate-to-source voltage which

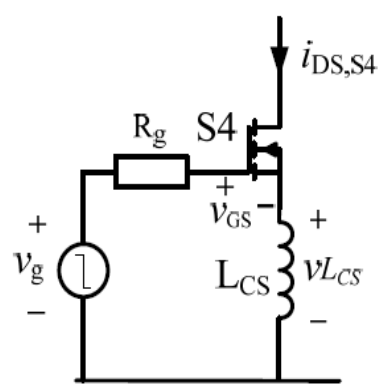

Fig. 12. Common source inductance acting as additional voltage in the gate driver circuit. 
TABLE V

Magnetic Parameters of PIM Module

\begin{tabular}{|c|c|}
\hline Parameters & Values \\
\hline Number of turns in primary $\left(N_{I}=N_{2}\right)$ & 2 \\
\hline Turns ratio of each transformer & $1: 4$ \\
\hline $\begin{array}{c}\text { Number of turns for the inductors } \\
\left(N_{L I}=N_{L 2}\right)\end{array}$ & 2 \\
\hline Each air gap length $(l g)$ & $0.5 \mathrm{~mm}$ \\
\hline Core type & EILP 64 \\
\hline Core material & Ferrite N87 \\
\hline Copper thickness mount on PCB layer & $4 \mathrm{oz}(140 \mu \mathrm{m})$ \\
\hline Switching frequency & $100 \mathrm{kHz}$ \\
\hline
\end{tabular}

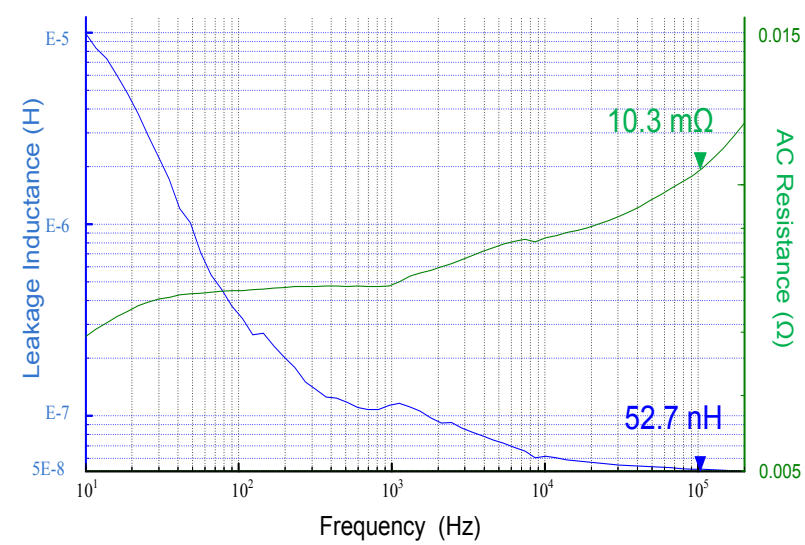

(a)

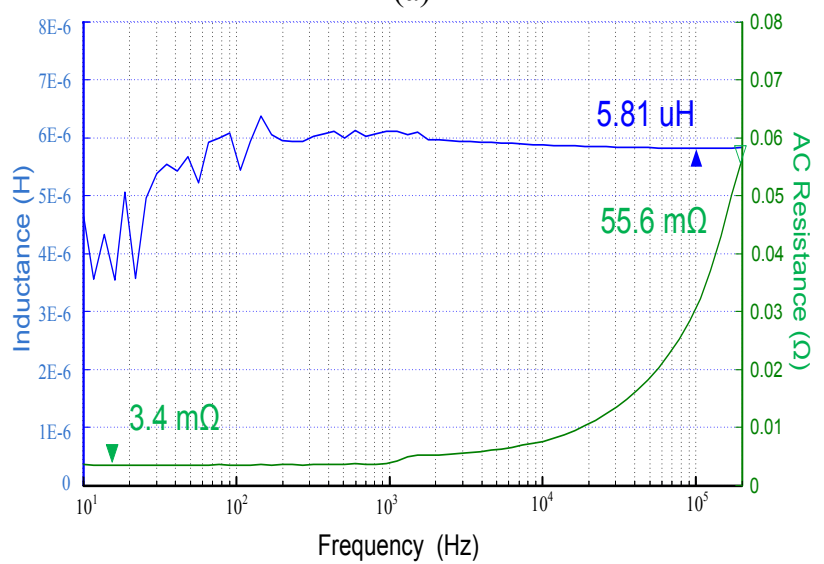

(b)

Fig. 13. Measurement results of impedance. (a) transformer $T_{1}$ or $T_{2}$. (b) Inductor $\mathrm{L}_{1}$ or $\mathrm{L}_{2}$.

may keep the MOSFET in its active region together with a high drain-to-source voltage. So this extra voltage will behave as a negative feedback in the switching seep, putting an upper limit to it. A detailed analysis on two commutation types, namely voltage limited and MOSFET limited commutations, during the turn-off of MOSFET is obtained in [46]. The boundary expression determining the commutation mode is,

$$
\frac{L_{X}}{L_{C S}}=\left(V_{C}-\frac{V_{0}}{2 n}\right) \cdot\left(\frac{1}{2 \cdot V_{G S}\left(i_{S}\right)}+\frac{2 n}{V_{0}}\right)
$$

where $L_{X}$ is composed of the leakage inductance and stray inductance due to the converter layout. $L_{C S}$ is the common source

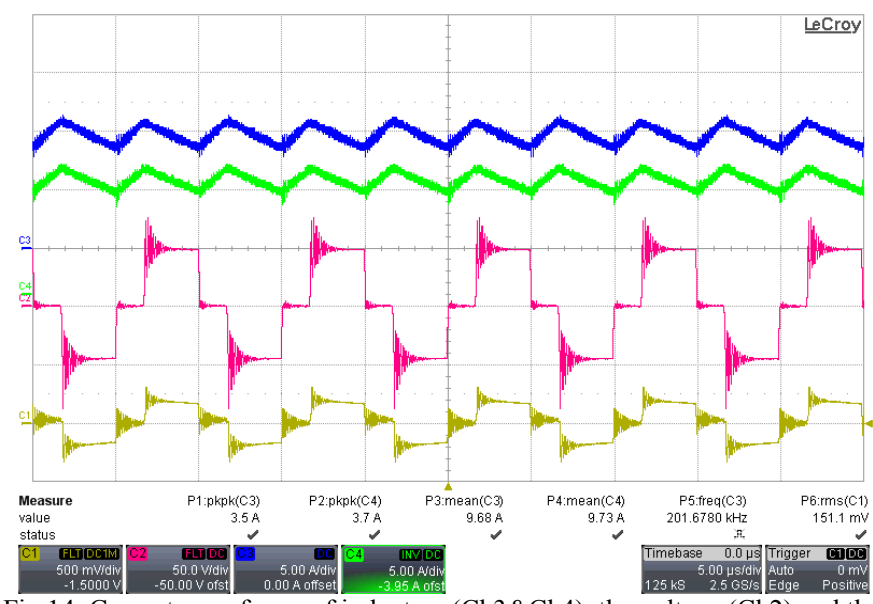

Fig.14. Current waveforms of inductors $(\mathrm{Ch} 3 \& \mathrm{Ch} 4)$, the voltage $(\mathrm{Ch} 2)$ and the current (Ch1) of $\mathrm{T}_{1}$

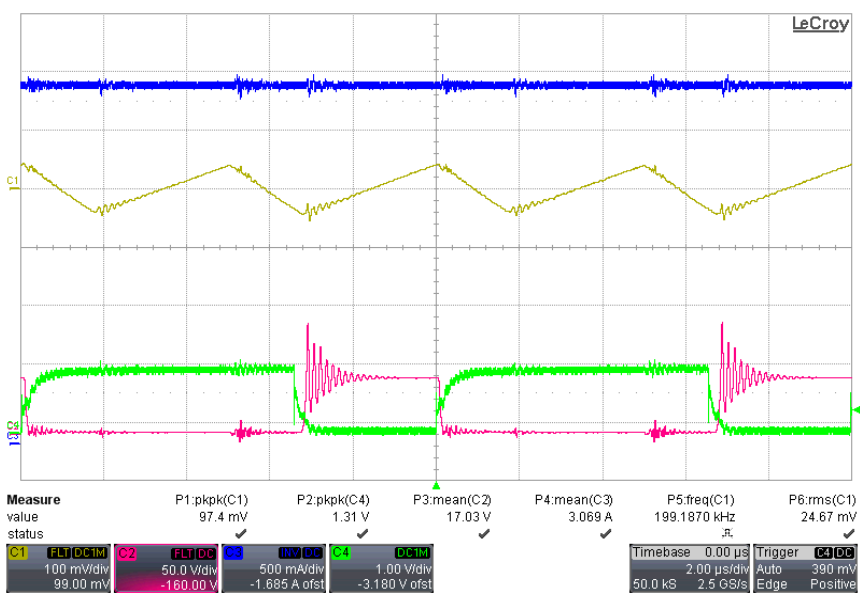

Fig.15. Total inductor current ripple (Ch1, AC coupled) and output current (Ch3), $\mathrm{V}_{\mathrm{DS}}(\mathrm{Ch} 2)$ and $\mathrm{V}_{\mathrm{GS}}(\mathrm{Ch} 4)$ of $\mathrm{S}_{1}$.

inductance including the internal package inductance and the package source pin inductance. $V_{G S}\left(i_{S}\right)$ is the gate voltage corresponding to the drain at the start of the turn-off process. $V_{C}$ is the clamp voltage which may be provided by an external clamp circuit or the avalanche voltage of the MOSFET. Table IV shows the corresponding values of these parameters used in this paper. In order to have a practical value for $L_{C S}, 7 \mathrm{nH} / \mathrm{cm}$ rule of thumb has been used. The stay and leakage inductance $L_{X}$ can be found in the measurement results of Section VI. The condition in (19) can be tested for this case by inserting the parameters of Table IV which results in,

$$
\frac{L_{X}}{L_{C S}}<\left(V_{C}-\frac{V_{0}}{2 n}\right) \cdot\left(\frac{1}{2 \cdot V_{G S}\left(i_{S}\right)}+\frac{2 n}{V_{0}}\right) .
$$

This result confirms the commutation mode as MOSFET limited commutation as explained in [1]. Therefore, in this case the expression for the switching losses per full bridge is,

$$
P_{S}=f \cdot\left[1+\frac{V_{0}}{4 \cdot n \cdot V_{G S}\left(i_{S}\right)} \cdot L_{C S}+L_{X}\right] \cdot I_{\text {Lpeak }}{ }^{2}
$$

\section{EXPERIMENTAL RESULTS}

\section{A. Results of PIM module}

A 2-kW prototype has been built to verify the new integrated magnetics design approach. Input voltage is between $20-50 \mathrm{~V}$ 


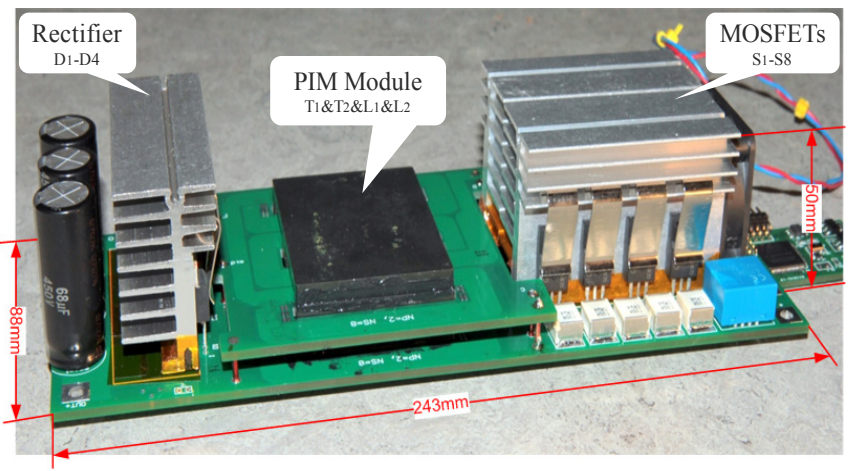

(a)

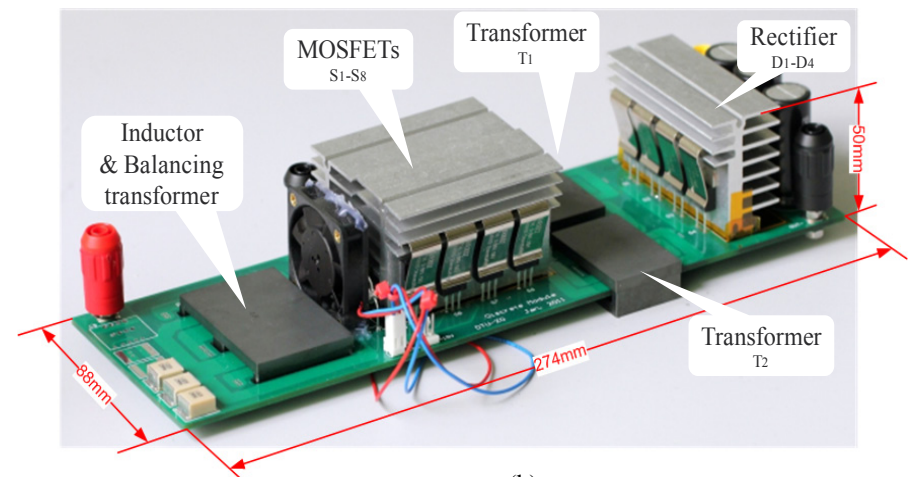

(b)

Fig. 16. Photo of experimental prototype converters (a) with PIM module (b) with single inductor, integrated balancing transformers and discrete transformers.

TABLE VI

CONVERTER POWER LOSS BREAKDOWN AT 45-V INPUT, 400-V OUTPUT AND 1.5-KW OUTPUT POWER

\begin{tabular}{|c|c|c|c|}
\hline \multirow{2}{*}{ Components } & \multicolumn{2}{|c|}{ Loss Type } & Loss (W) \\
\hline \multirow{2}{*}{ PIM module } & Winding loss & $\mathrm{T}_{1} \& \mathrm{~T}_{2}$ & $5.2 \mathrm{~W}$ \\
\cline { 2 - 3 } & $\mathrm{L}_{1} \& \mathrm{~L}_{2}$ & $2.0 \mathrm{~W}$ \\
\cline { 2 - 3 } & Core loss & $37.8 \mathrm{~W}$ \\
\hline \multirow{2}{*}{$\begin{array}{c}\text { MOSFET } \\
8 \text { pcs. }\end{array}$} & Conduction & $2.3 \mathrm{~W}$ \\
\cline { 2 - 3 } $\begin{array}{c}\text { Diodes } \\
4 \text { pcs. }\end{array}$ & Switching Loss & $9.9 \mathrm{~W}$ \\
\cline { 2 - 3 } & Conduction & $5.9 \mathrm{~W}$ \\
\hline \multicolumn{2}{|c|}{ Switching Loss } & $1.8 \mathrm{~W}$ \\
\hline
\end{tabular}

and output voltage is $400 \mathrm{~V}$. Primary switches are IPA028N08N3, 80-V, 2.8-m $\Omega$ power MOSFETs from Infineon. Output rectification is handled by Silicon Carbide Schottky diodes C3D10060A with 1.5-V forward voltage drop. Magnetic parameters of the PIM module are shown in Table V. One set of EELP-64 core and an additional piece of I-64 core, all composed of N87 core material. The core material selection is directly related to the core loss. In order to feature a lower core loss, ferrite materials are usually chosen as a suitable transformer's core material operating around hundreds kilo-hertz. Each transformer turns ratio is 1:4 $(n=4)$. Air gaps with $0.5-\mathrm{mm}$ length are used for the energy storage inductors $L_{1}$ and $L_{2}$. 4-oz copper thickness is used for PCB windings. Switching frequency is 100$\mathrm{kHz}$ with inductor current ripple of $200-\mathrm{kHz}$. The frequency selection does not affect the integrated operation principle and the same advantages for the PIM module are achieved regardless of the frequency. And the size of converter can be further reduced if a high frequency is selected. But it is note that the frequency selection is related to the optimization design. Higher frequency may cause a higher power loss due to a high frequency eddy current effect in the windings, higher core loss in the magnetic material and higher switching loss of power MOSFETs. In addition, higher frequency causes a higher maximum output capability of the PIM module (PIM module can be operated under a high power level if a high frequency is selected).

Interleaved winding technique shown in Fig.10 is utilized to
TABLE VII

CONVERTER POWER LOSS BREAKDOWN AT 30-V INPUT, 400 -V OUTPUT AND 1.5-KW OUTPUT POWER

\begin{tabular}{|c|c|c|c|}
\hline Components & \multicolumn{2}{|c|}{ Loss Type } & Loss (W) \\
\hline \multirow{3}{*}{ PIM module } & \multirow{2}{*}{ Winding loss } & $\mathrm{T}_{1} \& \mathrm{~T}_{2}$ & $7.9 \mathrm{~W}$ \\
\hline & & $\mathrm{L}_{1} \& \mathrm{~L}_{2}$ & $5.3 \mathrm{~W}$ \\
\hline & \multicolumn{2}{|c|}{ Core loss } & $22 \mathrm{~W}$ \\
\hline \multirow{2}{*}{$\begin{array}{l}\text { MOSFET } \\
8 \text { pcs. }\end{array}$} & \multicolumn{2}{|c|}{ Conduction } & $4.6 \mathrm{~W}$ \\
\hline & \multicolumn{2}{|c|}{ Switching Loss } & $22 \mathrm{~W}$ \\
\hline \multirow{2}{*}{$\begin{array}{l}\text { Diodes } \\
4 \text { pcs. }\end{array}$} & \multicolumn{2}{|c|}{ Conduction } & $7.9 \mathrm{~W}$ \\
\hline & \multicolumn{2}{|c|}{ Switching Loss } & $2.3 \mathrm{~W}$ \\
\hline \multicolumn{3}{|c|}{ Total loss } & $67.7 \mathrm{~W}$ \\
\hline
\end{tabular}

reduce the ac resistances and the leakage inductances. The measurement results for the integrated transformers and inductors are shown in Fig.13, obtained by PSM1735, impedance analyzer. The ac resistance and leakage inductance are obtained by opening secondary side and shorting both primary sides. The results in the figure have been referred to the primary side. Assuming that $T_{1}$ and $T_{2}$ have the same parameters, 52.7-nH leakage inductance and $10.3-\mathrm{m} \Omega$ ac resistance referred to the primary sides of each transformer can be derived. The stray parameters of the circuit are also included in the measurement results. Keeping the PCB winding far to the airgap, the fringing effect of airgap causes ac resistance of the inductors, $L_{1}$ and $L_{2}$, is 16.4 times than their dc resistances. The ac resistance of each inductor is $55.6-\mathrm{m} \Omega$ when the inductor current ripple works at $200-\mathrm{kHz}$. According to the above measurement results, detailed breakdown of power losses for 1.5-kW PIM module at $45-\mathrm{V}$ input and $30-\mathrm{V}$ input can be found in Table VI and Table VII respectively. The core loss of PIM dominates over the total power loss especially for high input voltage like $45-\mathrm{V}$. The winding loss of PIM is far less than the core loss which may not an optimization case. The solution for this is to balance the core loss and winding loss by increasing the number of turns of primary. However, it is noted that the fully interleaving may not be implemented due to the PCB layer limitation; otherwise the cost of PCB manufacture will be extremely high. The switching loss dominates over the total power loss when the converter operates at low voltage input like $30-\mathrm{V}$. As seen from (20), the 


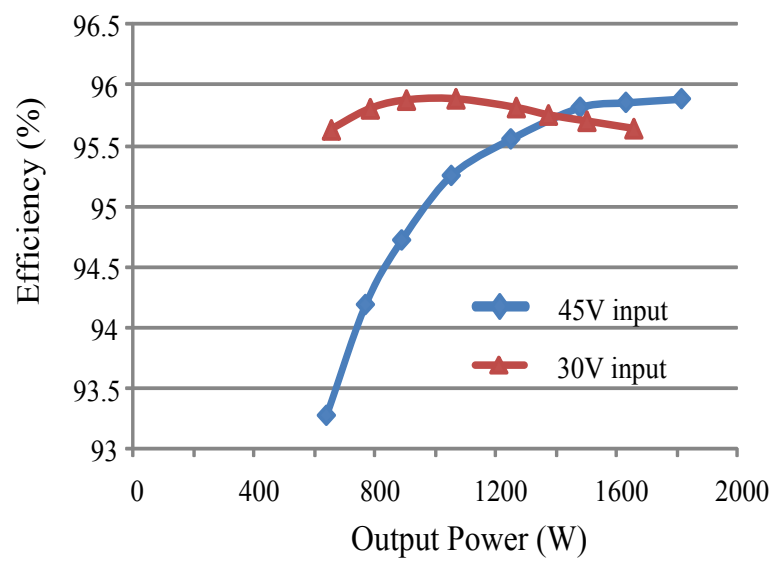

Fig. 17. Measured converter efficiency for PIM dc-dc converter.

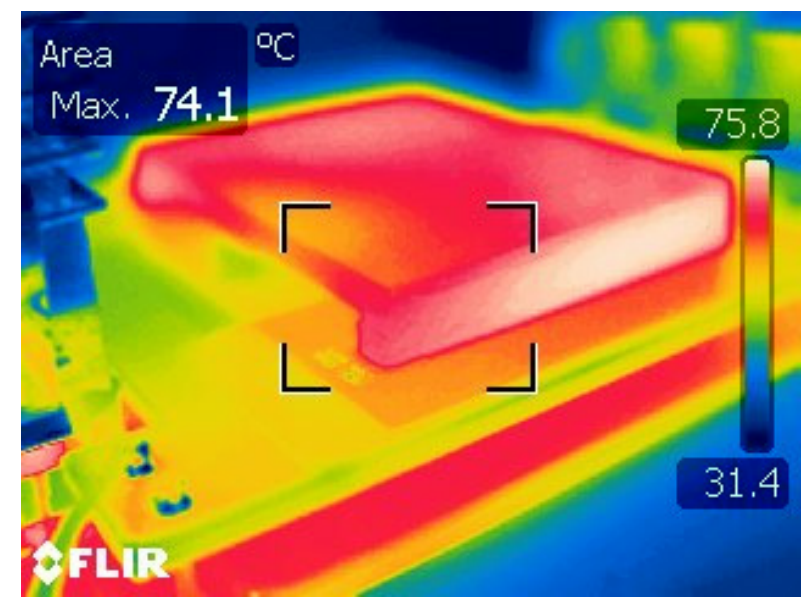

Fig. 18. Thermal photo of the PIM module at $45-\mathrm{V}$ input and $1.5-\mathrm{kW}$.

leakage inductance and stay inductance become very important in low voltage case. With the aforementioned solution of increased number of primary turns, the leakage inductance will be increased which allows a very high switching loss. Therefore, many tradeoffs exist in the PIM module and an optimization procedure needs to be done. However, this paper emphasis on the integration approach, the proof-concept demonstration rather than the optimization design.

IRS2110 high and low side gate drivers are used in the gate driver circuit together with ISO722C capacitive digital isolators for control signal protection. The control signals are produced by TMS28027 DSP. Fig.16-(a) shows the experimental prototype employing the proposed PIM module. Output is filtered by several 1-uF SMD capacitors in parallel placed very close to the rectifiers for minimizing the ac loop. When the converter operates at $100-\mathrm{kHz}, 30-\mathrm{V}$ input, $400-\mathrm{V}$ output and $1.5-\mathrm{kW}$ output power, the current waveforms of inductors $(\mathrm{Ch} 3 \& \mathrm{Ch} 4)$, the voltage $(\mathrm{Ch} 2)$ and the current $(\mathrm{Ch} 1)$ of transformer $T_{1}$ are presented in Fig.14. Observe that the two currents are identical. Removing oscilloscope offset, causes current traces to fully coincide. Also the total inductor current ripple (Ch1, AC coupled) and output current (Ch3), $\mathrm{V}_{\mathrm{DS}}(\mathrm{Ch} 2)$ and $\mathrm{V}_{\mathrm{GS}}(\mathrm{Ch} 4)$ of $S_{I}$ are shown in Fig.15 respectively.

High stability $(<10 \mathrm{ppm}) 0.1 \%$ shunt resistors are used for high precision of the efficiency measurements. Agilent 34410A high precision multimeters are used for all measurements. Current sense signals are shielded and fitted with common mode filters. Efficiency curves of the converter employing the PIM
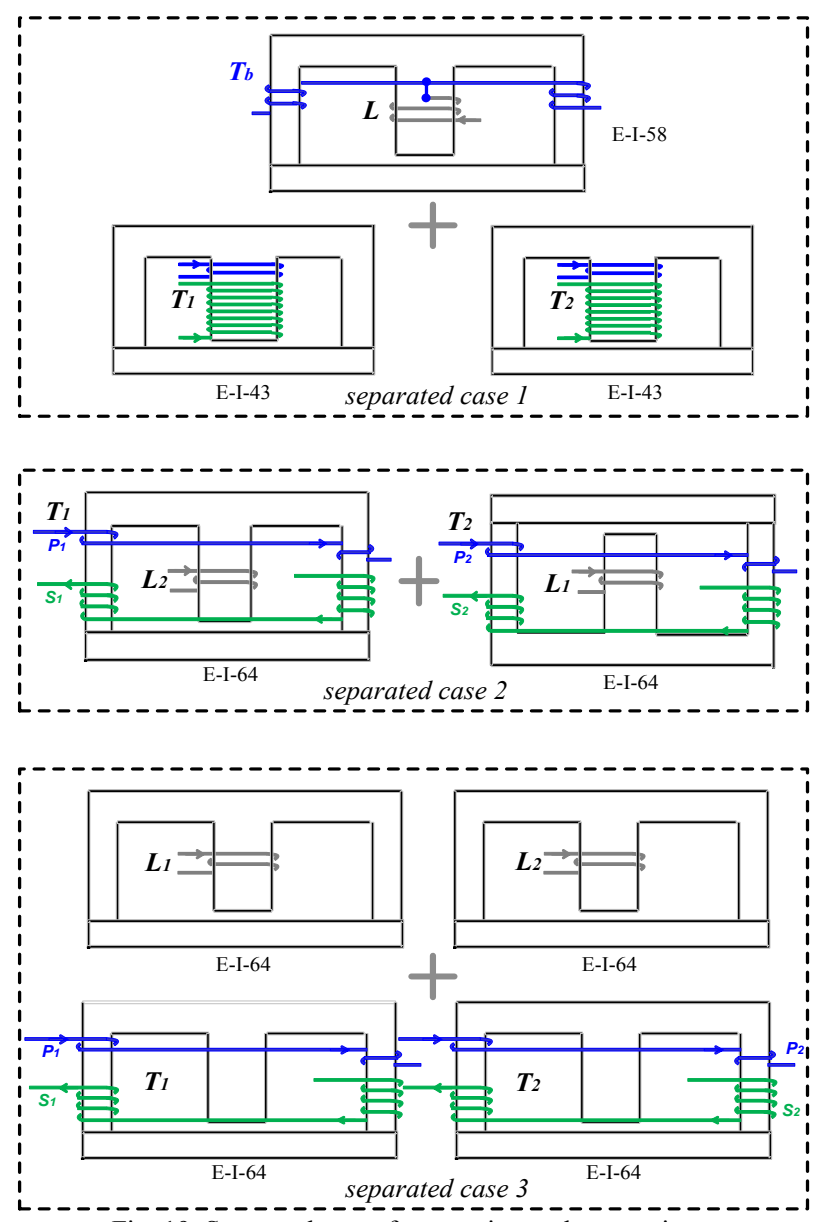

Fig. 19. Separated cases for experimental comparisons.

module when the output voltage is $400-\mathrm{V}$ are shown in Fig.17. Maximum efficiency of $95.9 \%$ has been observed with $45-\mathrm{V}$ input voltage, $400-\mathrm{V}$ output voltage and $1.8-\mathrm{kW}$ output power. And the same maximum efficiency can be observed at $30-\mathrm{V}$ input voltage, $400-\mathrm{V}$ output voltage and $1-\mathrm{kW}$. In low output power, the efficiency of $30-\mathrm{V}$ input is much higher than that of $45-\mathrm{V}$ input this is due to the fact that the low number of primary turns in this case causes the core loss of PIM dominating over the total power loss which has been mentioned in the previous. With increased output power, the switching loss becomes a crucial part in total power loss. Therefore, a lower efficiency at $30-\mathrm{V}$ input can be observed. Fig. 18 shows a thermal photo of PIM module at $45-\mathrm{V}$ and $1.5-\mathrm{kW}$ in which is the worst case for the core loss. Notice that a forced air flow from fan is used for cooling down the converter. As shown in the photo, the heat mostly concentrates on the side legs rather than the center leg. This is coincident with the analysis of core loss in section V.

\section{B. Comparison}

In order to demonstrate the advantages of PIM such as low profile and high efficiency, a comparison between the PIM and three different separated cases has been done. In order to make a fair comparison, all switching devices, gate drivers, and capacitors are kept the same. The prototype of separated case- 1 is shown in Fig.16-(b) which is consisted of single inductor with integrated balancing transformers and two discrete transformers. The detailed principle about this structure can be found in [26]. In separated case-1, two turns single inductor are wound in EILP-58 core with $0.5-\mathrm{mm}$ airgap length and two turns of integrated balancing transformer are wound in each side leg. The 
This article has been accepted for publication in a future issue of this journal, but has not been fully edited. Content may change prior to final publication.

TABLE VIII

Power Loss Breakdown of SeParated CASE-1 CONVERTER AT 45-V INPUT, 400-V OUTPUT AND 1.5-KW OUTPUT POWER

\begin{tabular}{|c|c|c|c|}
\hline Components & \multicolumn{2}{|c|}{ Loss Type } & Loss (W) \\
\hline \multirow{3}{*}{ PIM module } & \multirow{2}{*}{ Winding loss } & $\mathrm{T}_{1} \& \mathrm{~T}_{2}$ & $14.8 \mathrm{~W}$ \\
\hline & & $\mathrm{L}_{1} \& \mathrm{~T}_{\mathrm{b}}$ & $8.2 \mathrm{~W}$ \\
\hline & \multicolumn{2}{|c|}{ Core loss } & $28.5 \mathrm{~W}$ \\
\hline \multirow{2}{*}{$\begin{array}{l}\text { MOSFET } \\
8 \text { pcs. }\end{array}$} & \multicolumn{2}{|c|}{ Conduction } & $6.4 \mathrm{~W}$ \\
\hline & \multicolumn{2}{|c|}{ Switching Loss } & $17.8 \mathrm{~W}$ \\
\hline \multirow{2}{*}{$\begin{array}{l}\text { Diodes } \\
4 \text { pcs. }\end{array}$} & \multicolumn{2}{|c|}{ Conduction } & $7.4 \mathrm{~W}$ \\
\hline & \multicolumn{2}{|c|}{ Switching Loss } & $3.7 \mathrm{~W}$ \\
\hline \multicolumn{3}{|c|}{ Total loss } & $86.8 \mathrm{~W}$ \\
\hline
\end{tabular}

two discrete transformers are both employing EILP-43 cores with two turns in primary sides and 8 turns in secondary sides. N87 core material is used for all cores in the separated case-1. And full interleaved winding arrangement is also used in this case. The separated case- 2 is partially using integrated technology shown in Fig.19. The PCB winding and core size are kept the same with PIM module. Two E-I cores have been separated by adding a single I-core on the basis of PIM module. A single inductor and a single transformer are still integrated into the E-I core. A complete separation has been implemented in the separated case-3, consisting of four discrete magnetic components, $L_{1}, L_{2}, T_{1}$ and $T_{2}$. And the windings of transformer still keep the same arrangements with PIM module shown in Fig.19. The two inductors and two transformers are using the same core geometry EILP-64. Obviously, the PIM module has the smallest footprint and fewest numbers of components compared to the other separated cases. Fig.20 and Fig.21 show the efficiency comparisons among the four cases at $45-\mathrm{V}$ input and $30-\mathrm{V}$ input respectively. Regarding to the power losses of the separate case- 2 and case- 3 , the only difference with PIM case is to have higher core loss. This is because the flux is cancelled in the shared I-core in PIM case, causing a lower core loss. Winding layouts are not changed and thus the other power losses are kept the same with PIM case. From the efficiency curves, the case- 2 and case- 3 almost have the same core loss at $45-\mathrm{V}$ input and the PIM has $1 \%$ improvement at $1.5-\mathrm{kW}$ output power. When the input voltage is $30-\mathrm{V}$, the efficiency of the separated case-3 is slightly higher than that of the case-2. The PIM case has almost $0.5 \%$ improvement at $1.5-\mathrm{kW}$ output power. Regarding to the separated case-1, some design parameters including the number of turns of integrated balancing transformers, the winding widths, the winding lengths, the winding arrangements and the core geometries are different with the PIM case. Therefore, the difference in power loss between the PIM case and the case- 1 is not only the core loss, but also the winding loss and the switching loss. The power loss breakdown for separated case-1 is shown in Table VIII. From the efficiency figures, the separated case-1 has lower efficiencies than the PIM case at nominal output power. Notice that the comparison between the PIM case and separated case- 1 is not fair since the two cases are both not optimized. And the efficiency of separated case- 1 might be improved by changing winding widths and winding

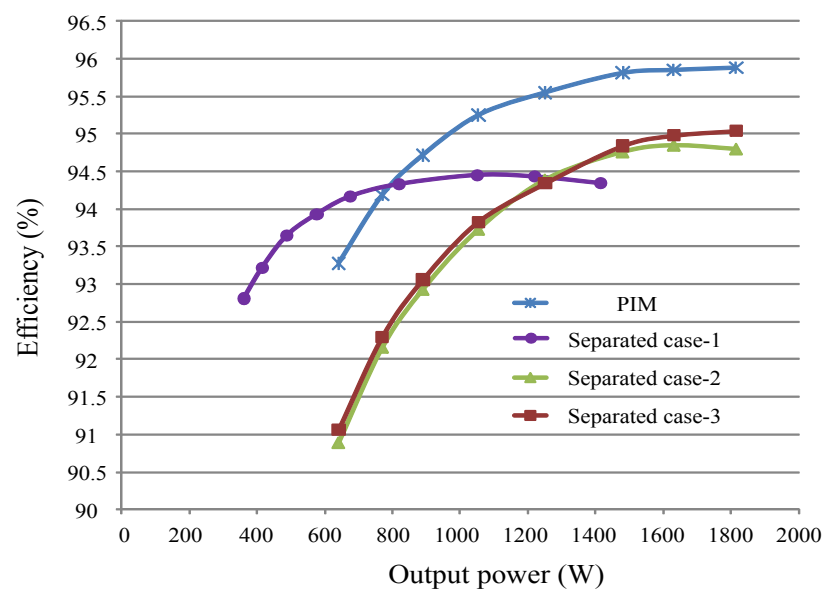

Fig. 20. Efficiency comparison at $45-\mathrm{V}$ input and $400-\mathrm{V}$ output.

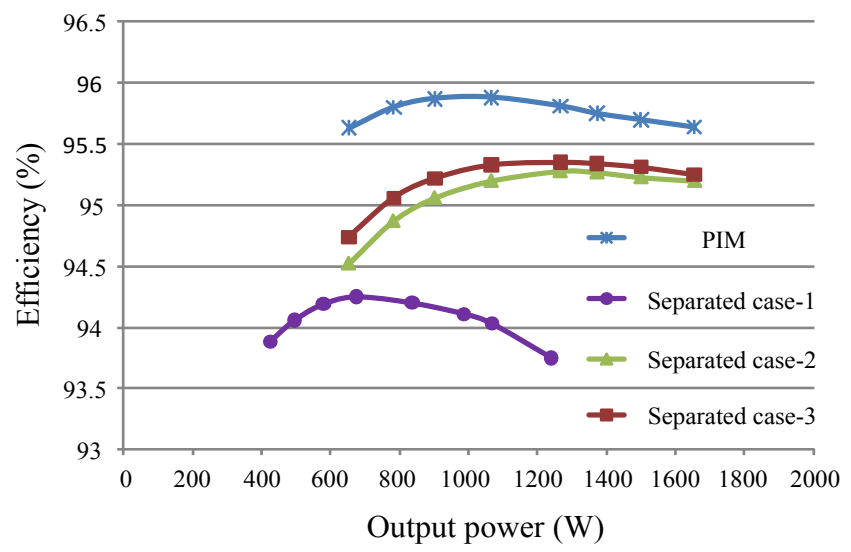

Fig. 21. Efficiency comparison at $30-\mathrm{V}$ input and $400-\mathrm{V}$ output.

arrangements and enhancing the value of inductor. Larger core geometries could also be used for the efficiency improvement. However, the power density (larger core geometries) and the cost (more PCB layers for higher inductance) will be lost if the aforementioned methods are used.

\section{Conclusion}

This work presents a new integrated magnetics approach to combine all magnetic components of the primary-parallel isolated boost converter into an E-I-E core structure. Since the design approach allows the transformers and inductors are electromagnetically uncoupled, it can be extended into many other isolated dc-dc topologies where multiple transformers and multiple inductors are involved in. The similar matter results are achieved for the extended topologies and all the advantages aforementioned will not be losing. The design approach provides a low footprint, low cost and high efficiency. Also, the integrated magnetics with planar components are made from pre-formed assemblies, thus the assembly process itself has only a few stages. This simplification of assembly allows the PIM to be manufactured with very high repeatability and with increased accuracy. The drawback of the PIM module is to limit the maximum the output power capability due to the overlapped flux. The detailed limitation of power capability has been presented and analyzed. Power loss analysis of the converter has been investigated in-depth. Test results from a $2-\mathrm{kW}$ experimental prototype verify that converter employing the PIM module is fully functional and electromagnetically equivalent. An 
efficiency of $95.9 \%$ can be achieved during $1.5-\mathrm{kW}$ nominal operating conditions. Experimental comparisons between the PIM module and three separated cases have illustrated the PIM module has advantages of lower footprint and higher efficiencies.

\section{APPENDIX}

In this appendix it is shown that the two transformers $T_{1}$ and $T_{2}$ have a partial coupling effect. The equivalent magnetic reluctance model between $T_{1}$ and $T_{2}$ is shown in the bottom of Fig.4.

$$
\begin{aligned}
& N_{1} \cdot i_{m 1}=\Phi_{1} \cdot\left(2 R_{1}+R_{2}\right)+\left(\Phi_{1}-\Phi_{2}\right) \cdot R_{2} \\
& N_{2} \cdot i_{m 2}=\Phi_{2} \cdot\left(2 R_{1}+R_{2}\right)+\left(\Phi_{2}-\Phi_{1}\right) \cdot R_{2}
\end{aligned}
$$

Combining (21) and (22), the following equations are obtained,

$$
\begin{gathered}
\Phi_{1}=\frac{2 \cdot N_{1} \cdot\left(R_{1}+R_{2}\right)}{\Delta} \cdot i_{m 1}+\frac{N_{2} \cdot R_{2}}{\Delta} \cdot i_{m 2} \\
\Phi_{2}=\frac{N_{1} \cdot R_{2}}{\Delta} \cdot i_{m 1}+\frac{2 \cdot N_{2} \cdot\left(R_{1}+R_{2}\right)}{\Delta} \cdot i_{m 2}
\end{gathered}
$$

where

$$
\Delta=4 \cdot R_{1}{ }^{2}+8 \cdot R_{1} \cdot R_{2}+3 \cdot R_{2}{ }^{2}
$$

Taking the partial derivative in (23) and (24),

$$
\begin{aligned}
& N_{1} \cdot \frac{d \Phi_{1}}{d t}=\frac{2 \cdot N_{1}{ }^{2} \cdot\left(R_{1}+R_{2}\right)}{\Delta} \cdot \frac{d i_{m 1}}{d t}+\frac{N_{1} \cdot N_{2} \cdot R_{2}}{\Delta} \cdot \frac{d i_{m 2}}{d t} \\
& N_{2} \cdot \frac{d \Phi_{2}}{d t}=\frac{N_{1} \cdot N_{2} \cdot R_{2}}{\Delta} \cdot \frac{d i_{m 1}}{d t}+\frac{2 \cdot N_{2}{ }^{2} \cdot\left(R_{1}+R_{2}\right)}{\Delta} \cdot \frac{d i_{m 2}}{d t}
\end{aligned}
$$

(27) is rewritten from (25) and (26),

$$
\begin{aligned}
& {\left[\begin{array}{l}
\lambda_{1} \\
\lambda_{2}
\end{array}\right]=\left[\begin{array}{cc}
\frac{2 \cdot N_{1}{ }^{2} \cdot\left(R_{1}+R_{2}\right)}{\Delta} & \frac{N_{1} \cdot N_{2} \cdot R_{2}}{\Delta} \\
\frac{N_{1} \cdot N_{2} \cdot R_{2}}{\Delta} & \frac{2 \cdot N_{2}{ }^{2} \cdot\left(R_{1}+R_{2}\right)}{\Delta}
\end{array}\right] \cdot\left[\begin{array}{l}
i_{m 1} \\
i_{m 2}
\end{array}\right]} \\
& =\left[\begin{array}{ll}
L_{11} & L_{M} \\
L_{M} & L_{22}
\end{array}\right] \cdot\left[\begin{array}{l}
i_{m 1} \\
i_{m 2}
\end{array}\right]
\end{aligned}
$$

where the flux linkages $\lambda_{1}$ and $\lambda_{2}$ are the time integrals of the transformer primary voltages, $i_{m 1}$ and $i_{m 2}$ are the individual excitation currents. $L_{11}$ and $L_{22}$ are their self-inductances. $L_{M}$ represents mutual inductance between the two transformer windings. With assumption that leakage flux through the air is negligible, (28) (30) can be obtained,

$$
\begin{gathered}
L_{m 1}=L_{11}+L_{M}=\frac{N_{1}{ }^{2}}{2 \cdot R_{1}+R_{2}} \\
L_{m 2}=L_{22}+L_{M}=\frac{N_{2}{ }^{2}}{2 \cdot R_{1}+R_{2}}
\end{gathered}
$$

$$
k=\frac{L_{M}}{L_{11}}=\frac{R_{2}}{2 \cdot\left(R_{1}+R_{2}\right)}
$$

The results of magnetizing inductance of transformers are the same with that in Section III. $k$ represents the coupling coefficient between $T_{1}$ and $T_{2}$. According to the geometry of core, $k=0.4$ can be obtained for their coupling coefficient.

\section{REFERENCES}

[1] M. Nymand and M. A. E. Andersen, "New primary-parallel boost converter for high-power high gain applications," in Proc. IEEE APEC, 2009, pp. 35-39.

[2] P. Xu, M. Ye, P. Wong and F. C. Lee, "Design of 48 V voltage regulator modules with a novel integrated magnetics," IEEE Trans. on Power Electron., vol.17, no.6, pp.990-998, Nov.2002.

[3] J. Sun, K. F. Webb, and V. Mehrotra, "Integrated magnetics for currentdoubler rectifiers," IEEE Trans. on Power Electron., vol. 19, no. 3, pp.582590, May, 2004.

[4] J. Sun, V. Mehrotra, "Orthogonal winding structures and design for planar integrated magnetics," IEEE Trans. on Ind. Electron., vol. 55, no. 3, pp.1463-1469, March, 2008.

[5] W. Chen, G. Hua, D. Sable and F. C. Lee, "Design of high efficiency, low profile, low voltage converter with integrated magnetics," in Proc. IEEE APEC, 1997, pp. 911-917.

[6] P. Xu, Q. Wu, P. Wong and F. C. Lee, "A novel integrated current doubler rectifier," in Proc. IEEE APEC, 2000, pp. 735-740.

[7] R. Chen, S. J. T., van Wyk J.D. "Design of planar integrated passive module for zero-voltage-switched asymmetrical half-bridge PWM converter," IEEE Trans. on Ind. Appl., Vol. 39, no.36, pp.1648-1655, Nov.Dec. 2003.

[8] P.A. J. van Rensburg, J.D. van Wyk and J.A. Ferreira, "Design, prototyping and assessment of a $3 \mathrm{~kW}$ integrated LCT component for development in various resonant converters," IET Power Electron., Vol. 2, no.5, pp.535-544, 2009.

[9] J. T. Strydom, J. A. Ferreira, J. D. van Wyk, I. W. Hofsajer, E. Waffenschmidt, "Power electronic subassemblies with increased functionality based on planar sub-components," in Proc. IEEE PESC, 2000, pp. 1273-1278.

[10] M. J. Prieto, A. M. Pernía, J. M. Lopera, J. Á. Martínez, and F. Nuño, "Turn-Coupling in Thick-Film Integrated Magnetic Components for Power Converters," IEEE Trans. on Components and Packaging Technologies, vol.31, no.4, pp.837-848, Dec.2008.

[11] E. de Jong, J. Ferreira, P. Bauer, "Toward the next level of PCB usage in power electronic converters," IEEE Trans. on Power Electron., vol.23, no.6, pp.3153-3163, Nov. 2008.

[12] C. Quinn, K. Rinne, T. O'Donnell, M. Duffy, C.O. Mathuna, "A review of planar magnetic techniques and technologies," in Proc. IEEE APEC, 2001, pp. $1175-1183$.

[13] C. Buccella, C. Cecati and F. de Monte, "A coupled electrothermal model for planar transformer temperature distribution computation" IEEE Trans. on Ind. Electron., Vol. 55, no.10, pp.3583-3590, Oct. 2008.

[14] L. Yan and B. Lehman, "An integrated magnetic isolated two-inductor boost converter: analysis, design and experimentation" IEEE Trans. on Power Electron., vol.20, no.2, pp.332-342, March.2005.

[15] L-P. Wong, Y-S. Lee, M. H. L. Chow, and D. K-W Cheng, "A four-phase forward converter using an integrated transformer," IEEE Trans. on Ind. Electron., vol. 55, no. 2, pp.817-831, March, 2008.

[16] S-Y Lee, A. G. Pfaelzer, and J. D. van Wyk, "Comparison of different designs of a 42-V/14-V dc/dc converter regarding losses and thermal aspects" IEEE Trans. on Ind. Appl., vol.43, no.2, pp.520-530, Mar.2007.

[17] P-L. Wong, Q-Q. Wu, P. Xu, B. Yang and F. C. Lee, "Investigating coupling inductors in the interleaving QSW VRM," in Proc. IEEE APEC, 2000, pp. 973-978.

[18] H. Kosai, S. McNeal, B. Jordan, J. Scofield, B. Ray and Z. Turgut, "Coupled inductor characterization for a high performance interleaved boost converter," IEEE Trans. on Magn., vol.45, no.10, pp.4812-4815, Oct.2009.

[19] Z. Ouyang, O. C. Thomsen, M. A. E. Andersen and T. Björklund, "Low Profile, Low Cost, New Geometry Integrated Inductors," in Proc. IEEE APEC, pp.150-156, March, 2011.

[20] R. Prieto, R. Asensi, J. A. Cobos and J. Uceda, "A full procedure to model integrated magnetics based on FEA," in Proc. IEEE APEC, pp. 952- 957, 2004 . 
[21] M. T. Zhang, M. M. Jovanovic, F.C. Lee, "Analysis, design, and evaluation of forward converter with distributed magnetics-interleaving and transformer paralleling" in Proc. IEEE APEC, 1995, pp.315-321.

[22] D. Reusch and F. C. Lee, "High Frequency Bus Converter with Integrated Matrix Transformers for CPU and Telecommunications Applications," in Proc. IEEE ECCE, 2010, pp. 2446-2450.

[23] K. L. Poulsen, Z. Ouyang and G. Sen, "Hybrid isolated-boost/flyback operation with integrated magnetics for start-up and full voltage range output of isolated boost family converters" EP \& US Patent, 2011.

[24] M. Nymand and M. A. E. Andersen, "High-efficiency isolated boost dc-dc converter for high-power low-voltage fuel-cell applications," IEEE Trans. on Ind. Electron., Vol. 56, no.2, pp.505-514, Feb. 2010

[25] Z. Ouyang, Z. Zhang, O. C. Thomsen, M. A. E. Andersen, "Planar integrated magnetics (PIM) module in hybrid bidirectional dc-dc converter for fuel cell application," IEEE Trans. on Power Electron., 2011.

[26] G. Sen, Z. Ouyang, O. C. Thomsen, M. A. E. Andersen, "Integrated current balancing transformer for primary parallel isolated boost converter," in Proc. EPE, 2011.

[27] Z. Ouyang, G. Sen, O. C. Thomsen, M. A. E. Andersen. "Fully integrated planar magnetics for primary-parallel isolated boost converter," in Proc. IEEE APEC, pp.174-181, March, 2011.

[28] W. A. Roshen, "A practical, accurate and very general core loss model for nonsinusoidal waveforms," IEEE Trans. on Power Electron., vol.22, no.1, Jan. 2007.

[29] I. Villar, U. Viscarret, I. E.-Otadui, A. Rufer, "Global loss evaluation methods for nonsinusoidally fed medium-frequency power transformers," IEEE Trans. Ind. Electron., vol. 56, no.10, pp.4132-4140, Oct. 2009.

[30] J. Reinert, A. Brockmeyer, R. W. A. A. De Doncker, "Calculation of losses in ferro- and ferrimagnetic materials based on the modified Steinmetz equation," IEEE Trans. Ind. Appl., vol. 37, no. 4, pp. 1055-1060, Jul-Aug. 2001.

[31] J. Li, T. Abdallah, C. R. Sullivan, "Improved calculation of core loss with nonsinusoidal waveforms," in Proc. IEEE IAS, 2001, pp. 2203-2210.

[32] K. Venkatachalam, C. R. Sullivan, T. Abdallah, H. Tacca, "Accurate prediction of ferrite cores loss with nonsinusoidal waveforms using only Steinmetz parameters," in Proc. IEEE Workshop Comput. Power Electron., 2002, pp. 36-41.

[33] C. R. Sullivan, "Computationally efficient winding loss calculation with multiple windings, arbitrary waveforms, and two-dimensional or threedimensional field geometry" IEEE Trans. on Power Electron. vol. 16, no. 1, pp.142-150, 2001

[34] A. Van den Bossche, V. C. Valchev, G. B. Georgiev, "Measurement and loss model of ferrites with non-sinusoidal waveforms," in Proc.IEEE PESC, 2004, pp. 4814-4818.

[35] D. Lin, P. Zhou, W. N. Fu, Z. Badics, and Z. J. Cendes, "A dynamic core loss model for soft ferromagnetic and power ferrite materials in transient finite element analysis," IEEE Trans. on Magn., vol. 40, no. 2, pp.13181321, Mar. 2004.

[36] W. Shen, F.Wang, D. Boroyevich, and C. W. Tipton, "Loss characterization and calculation of nanocrystalline cores for high-frequency magnetics applications" IEEE Trans. on Power Electron., vol.23, no.1, Jan. 2008.

[37] J. Muhlethaler, J. Biela, J. W. Kolar, and A. Ecklebe, "Core losses under dc bias condition based on Steinmetz parameters," in Proc. of the IEEE/IEEJ International Power Electronics Conference (ECCE Asia),pp. 2430-2437, 2010.

[38] P. L. Dowell, "Effects of eddy currents in transformer windings," Proc. Inst. Elect. Eng., vol. 113, no. 8, pp. 1387-1394, Aug. 1966.

[39] W. G. Hurley, E. Gath, J. G. Breslin, "Optimizing the AC resistance of multilayer transformer windings with arbitrary current waveforms," IEEE Trans. on Power Electron., vol.15, no.2, pp.369-376, Mar. 2008.

[40] J. Ferreira, "Improved analytical modeling of conductive losses in magnetic components," IEEE Trans. on Power Electron., vol. 9, no. 1, pp. 127-131, Jan. 1994.

[41] Z. Ouyang, O. C. Thomsen and M. A. E. Andersen, "Optimal analysis and improved design of planar transformer in high power dc-dc converters" IEEE Trans. on Ind. Elec., 2011.

[42] Z. Ouyang, O. C. Thomsen, M. A. E. Andersen, "The analysis and comparison of leakage inductance in different winding arrangements for planar transformer," in Proc. IEEE PEDS, 2009, pp. 1143 - 1148.

[43] X. Nan, C. R. Sullivan, "An improved calculation of proximity-effect loss in high-frequency windings of round conductors," in Proc. IEEE PESC, 2003, pp.853-860

[44] W. A. Roshen, "High-frequency fringing fields loss in thick rectangular and round wire windings," IEEE Trans. on Magn., vol. 44, no. 10, pp.23962401, Oct. 2008.

[45] Peter Wallmeier, "Improved analytical modeling of conductive losses in gapped high-frequency inductors," IEEE Trans. on Ind. Appl., vol.37, no.4, pp.1045-1054, July.2001.
[46] M. Nymand, "High Efficiency Power Converter for Low Voltage High Power Applications", $\mathrm{PhD}$ dissertation. 2010

[47] S. Havanur, "Quasi-clamped inductive switching behaviour of power MOSFETs," in Proc. IEEE PESC 2008, Rhodes, Greece, pp. 4349-4354.

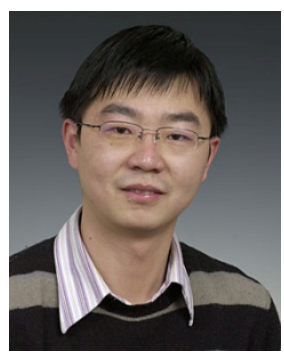

Ziwei Ouyang (S'07, M'11) received the B.S. degree in electrical engineering from the Naval University of Engineering, Wuhan, China, in 2004, the M.S degree from Tianjin University of Technology, Tianjin, China, in 2007, and the Ph.D. degree from the Technical University of Denmark, Kongens Lyngby, Denmark, in 2011.

From May 2011 to August 2011, he was with Technical University of Delft, Netherlands, as a Visiting Scholar. He is currently in the Department of Electrical Engineering, Technical University of Denmark, as a Postdoctoral Researcher. His current research interests include magnetics design, modeling and integration in power supplies, $\mathrm{dc} / \mathrm{dc}$ converters, and digital control in high-power reversible converters

Dr. Ouyang is a recipient of the Chinese Government Award for Outstanding Students Abroad in 2010 and received the best paper award in 2010 from IPEC (ECCE-Asia).

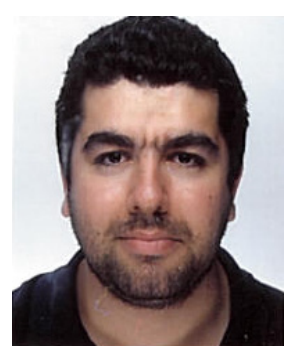

Gokhan Sen (S'09) received the B.S. degree in electrical and electronics engineering from the Middle East Technical University, Ankara, Turkey, in 2003, and the M.S. degree in electrical engineering from the University of Akron, Akron, OH, in 2008

From October 2003 to August 2006, he was with Marmara Research Center, The Scifinti and Technical Research Council of Turkey. He is currently continuing with his $\mathrm{PhD}$ studies in the Technical University of Denmark, Kongens Lyngby, Denmark. His main research interests include modeling and control of switch mode converters and design of planar integrated magnetics.

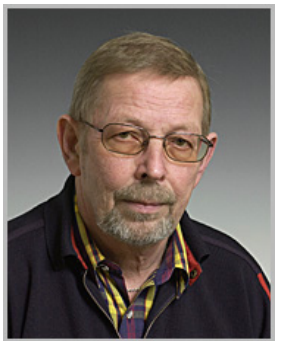

Ole C. Thomsen (M'06) received the B.S.E.E. degree in electronics from the Engineering Academy of Denmark (DIA), Kongens Lyngby, Denmark in 1970.

From 1970 to 1976 he was with Skandinavisk Teleindustri A/S as a RF R\&D engineer. From 1976 to 1980 he was with Christian Rovsing A/S as a Power Electronic Project Manager in the Space Department. In 1980 he founded Powerlab A/S, operating within R\&D and Manufacturing of professional Power Electronic, and was here until 2004 as a General Manager. Since 2005 he has been with the Technical University of Denmark where he currently is an Associate Professor. His main research interests include switch-mode power supplies, power factor correction and EMC.

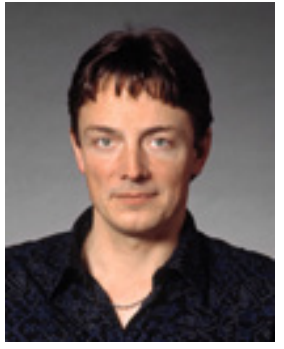

Michael A. E. Andersen (M'88) received the M.Sc.E.E. and Ph.D. degrees in power electronics from the Technical University of Denmark, Kongens Lyngby, Denmark, in 1987 and 1990, respectively.

$\mathrm{He}$ is currently a Professor of power electronics with the Technical University of Denmark, where he is Deputy Director at Department of Electrical Engineering as well as Head of the Danish Ph.D Research School in Electrical Energy Systems "EnergyLabDK". He has authored or coauthored over 100 papers. His research areas include switch-mode power supplies, piezoelectric transformers, power factor correction, and switchmode audio power amplifiers. 